\title{
Experimental Study on Dynamic Mechanical Properties of Coal Gangue Concrete
}

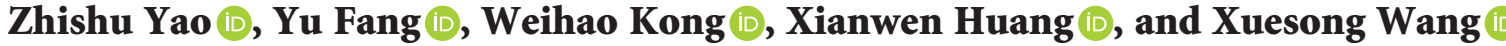 \\ School of Civil Engineering and Architecture, Anhui University of Science and Technology, Huainan, Anhui, China \\ Correspondence should be addressed to Zhishu Yao; zsyao@aust.edu.cn
}

Received 3 September 2020; Revised 7 November 2020; Accepted 11 November 2020; Published 23 November 2020

Academic Editor: J. M. P. Q. Delgado

Copyright ( $\odot 2020$ Zhishu Yao et al. This is an open access article distributed under the Creative Commons Attribution License, which permits unrestricted use, distribution, and reproduction in any medium, provided the original work is properly cited.

\begin{abstract}
In order to study the static and dynamic mechanical characteristics of the coal gangue concrete used in the mine support structure, the compressive strength test, the drop weight impact test, and the Split Hopkinson Pressure Bar (SHPB) test were conducted. The compressive strength, initial and final impacting energy, dynamic strength, and failure characteristic of concrete were obtained of the concrete single-doped with coal gangue coarse aggregate, single-doped with coal gangue fine aggregate, and codoped with coal gangue coarse and fine aggregates. The results show that (1) it is feasible that employing coal gangue to replace natural coarse and fine aggregates in concrete can prepare C30 and C40 concrete; (2) the addition of coal gangue fine aggregate has a positive effect on the impact energy of the initial and final cracks of concrete, while the addition of coal gangue coarse aggregate has a negative effect on it; (3) compared with the static strength, the dynamic strength of concrete is improved no matter whether coal gangue is added to concrete; (4) the incorporation of coal gangue coarse aggregate will make the concrete shear surface smooth; (5) at the given impacting pressure, the concrete with coal gangue coarse aggregate has greater particle breakage and those with coal gangue fine aggregate has less. The research of this study can be a reference for the application of gangue concrete in mine support structures.
\end{abstract}

\section{Introduction}

In recent years, the concept of sustainable development and ecological environmental protection has become deeply rooted in the hearts of people, and various countries have begun to attach importance to the protection of the natural environment and ecological balance [1-3]. In China, in order to protect the natural environment, many areas have implemented prohibit hillside mining prohibitions, which can result in problems for the supply of concrete aggregate for mine support near mountainous areas. In order to solve the concrete aggregate supply problem for mine support structures, scholars have tried to use coal gangue produced in the process of coal mining as concrete aggregate [4-7]. Coal gangue is the solid waste with the largest amount of emission in the process of coal mining. It is generally treated by way of placement in a storage yard, which takes up space in the storage yard, pollutes the environment, and affects the green development of the coal industry [8-10]. Using wasted coal gangue as concrete aggregate can reduce the environmental pollution caused by coal gangue stacking and protect the environment; further, it can reduce the demand for natural sand and rocks, as well as saving resources, which is an effective way to turn waste into high-value materials. Therefore, this research proposes having coal gangue directly crushed and screened under a mine as the construction technology to be used for coal gangue concrete preparation. This method not only solves the environmental problems caused by coal gangue but also addresses the concrete aggregate supply problem, giving it a good application prospect $[9,11,12]$.

Compressive strength is part of the basic mechanical indexes of concrete, and it is also the judgment standard for concrete whether available for engineering application $[13,14]$. Zhang et al. [5] studied the compressive strength of concrete with coal gangue and concluded that the compressive strength and splitting tensile strength might reduce when the coal gangue was mixed in the concrete and the reducing amplitude increased with the increase of mixing ratio. After that, for considering the working situation of concrete bearing cyclic loading, Li et al. [15] studied the compressive strength of concrete mixed with coal gangue 
under cyclic loading and obtained, that, at the given cyclic loading, the concrete with coal gangue has worse compressive strength than those without coal gangue. This result was explained by the accumulation of damage characteristics and the low strength of coal gangue. For supporting engineering of concrete with coal gangue corroded by acid solution, a series of concrete tests were conducted by Li et al. [3] and concluded that, in premise of low concrete strength requirements (less than $10 \mathrm{MPa}$ ), it is completely feasible to use coal gangue to replace the concrete coarse aggregate in acid solution. Then, for improving the compressive strength of concrete with coal gangue with high strength requirements, Ma et al. $[11,16]$ try to incorporate the appropriate alkali activator in coal gangue concrete. The experimental results demonstrate that the addition of an appropriate alkali activator can improve the compressive strength of coal gangue concrete. A large number of studies show that the direct addition of coal gangue in concrete is tended to reduce the compressive strength. Hence, it is essential to measure the compressive strength of coal gangue concrete and check the strength requirements before engineering application.

In coal mine support structures, except for the static pressure generated by the rock [17-19], the concrete is often subjected to dynamic load caused by construction and stope. However, fewer studies were conducted on the dynamic characteristic of concrete, especially in the concrete of coal gangue. Hence, for supporting coal mine supporting engineering, it is necessary to study the dynamic properties of concrete with coal gangue [20-22]. For measuring the dynamic properties of concrete, the drop weight impact test [23] and the SHPB (Split Hopkinson Pressure Bar) impact test [24] are proposed in recent years. The results of the drop weight impact test can better present the impact damage energy of the specimen [25]. Abid et al. [26,27] studied the impact failure characteristics of fiber-reinforced concrete by this method and analyzed the failure characteristic of concrete under impact loading. Through SHPB tests, the dynamic stress-strain relationship of concrete can be obtained [28]. By this method, Lee et al. [24] studied the dynamic stress-strain relationship of concrete and put forward a prediction model of concrete dynamic strength. At present, there is no relevant studies on the dynamic properties of concrete with coal gangue, which limits the promotion and application of coal gangue concrete.

Based on the above analysis, for supporting a coal mine supporting engineering in Huainan, China, the static and dynamic mechanical properties of coal gangue concrete were studied. In this paper, the compressive strength, initial and final impacting energy, dynamic strength, and failure characteristic of concrete were obtained of single-doping coal gangue coarse aggregate, single-doping coal gangue fine aggregate, and codoping coal gangue coarse and fine aggregates. The obtained results may be used for supporting the coal mine engineering.

\section{Materials and Solutions}

2.1. Test Materials. The cementitious materials used in the test were P.C32.5 and P.O42.5 Portland cement. The natural coarse aggregate was limestone macadam with continuous gradation, and the particle size range was $4.75-20 \mathrm{~mm}$. Natural fine aggregate was Huaihe River sand with a fineness modulus of 2.628. The water-reducing agent was PCA-1 polycarboxylic high-performance water-reducing agent, which is transparent and colorless, and the water-reducing rate was $25-35 \%$. The coal gangue used in this experiment was taken from the undisturbed coal gangue of the Dingji Coal Mine in Huainan. After being crushed by a crusher and sieved by a square-hole screen, fine aggregate with a particle size of $0.15-4.75 \mathrm{~mm}$ and coarse aggregate of continuous grading test of $4.75-20 \mathrm{~mm}$ were obtained. The fineness modulus of the coal gangue fine aggregate was 2.830 . The rock strength test results and the chemical composition of the coal gangue samples are shown in Tables 1 and 2, respectively.

It can be seen from Table 2 that, in the chemical composition of coal gangue, the mass fractions of $\mathrm{SiO}_{2}$ and $\mathrm{Al}_{2} \mathrm{O}_{3}$ accounted for a large proportion: $50.86 \%$ and $12.37 \%$, respectively. According to the classification relationship between the chemical composition of coal gangue and rock type, it was preliminarily determined that the coal gangue belonged to sandstone gangue. Compared with the seven indicators of coal gangue resource utilization (coal gangue type, rock type, fixed carbon content $\left(\mathrm{FC}_{\mathrm{ad}}\right)$, total sulfur content $(\mathrm{S}, \mathrm{d}), \mathrm{Al}_{2} \mathrm{O}_{3} / \mathrm{SiO}_{2}$ ratio, $\mathrm{Fe}_{2} \mathrm{O}_{3}$ content, and $\mathrm{CaO}+\mathrm{MgO}$ content), the chemical composition of the coal gangue met the requirements for coarse and fine aggregates of cement concrete $[3,4,6]$ (Figures 1 and 2).

\subsection{Mixture Proportion and Specimen Preparation.} According to the Specification for Mix Proportion Design of Ordinary Concrete (JGJ55-2019) [29], the benchmark mix design of concrete is shown in Table 3.

On the basis of C30 and C40 benchmark concrete mix proportions, coal gangue concrete was prepared by singledoped and codoped gangue coarse and fine coal gangue aggregate. Based on the pretest results and existing relevant research $[7,30]$, the replacement rates of coarse and fine aggregates of coal gangue were set at $100 \%$ and $30 \%$, respectively. The test scheme is shown in Table 4 .

For each ratio, 18 pieces of $100 \times 100 \times 100 \mathrm{~mm}$ cube specimens and 20 pieces of $\Phi 70 \times 35 \mathrm{~mm}$ cylindrical specimens were made to measure the compressive strength, falling weight impact performance, and SHPB impact performance of concrete. After pouring the test block, it was allowed to stand at room temperature for $24 \mathrm{~h}$ and then was removed from the mold. After numbering, it was placed into a curing box at a temperature of $20 \pm 2^{\circ} \mathrm{C}$ and humidity of $97 \%$ for standard curing.

\subsection{Test Methods}

2.3.1. Experimental Study on Compressive Strength of Coal Gangue Concrete. The compressive strength of concrete was tested according to "The Standard for Test Methods of Mechanical Properties of Ordinary Concrete" (GB/T500812019) [31]. In this test, cube specimens with a size of 
TABLE 1: Uniaxial compressive strength of noncombustible coal gangue.

\begin{tabular}{lccc}
\hline Coal gangue sample & $\# 1$ & $\# 2$ & \\
\hline Average rock strength $(\mathrm{MPa})$ & 57.64 & 60.31 & 65.26 \\
\hline
\end{tabular}

TABLe 2: Main chemical constituents of coal gangue.

\begin{tabular}{lccccccccc}
\hline Chemical composition & Loss & $\mathrm{SiO}_{2}$ & $\mathrm{Fe}_{2} \mathrm{O}_{3}$ & $\mathrm{Al}_{2} \mathrm{O}_{3}$ & $\mathrm{CaO}$ & $\mathrm{f}-\mathrm{CaO}$ & $\mathrm{MgO}$ & $\mathrm{SO}_{3}$ & $\sum$ \\
\hline Gangue (\%) & 17.31 & 50.86 & 6.3 & 12.37 & 7.43 & 0 & 3.81 & 0.13 & 98.21 \\
\hline
\end{tabular}

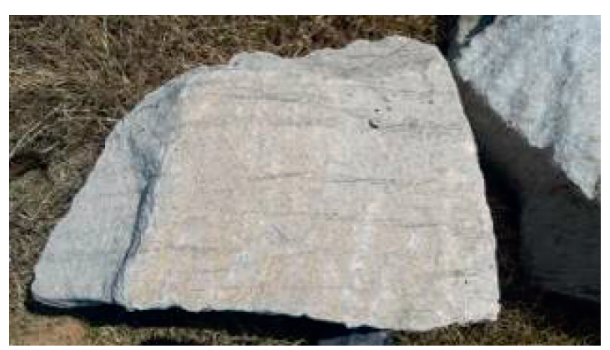

FIGURE 1: Undisturbed coal gangue.

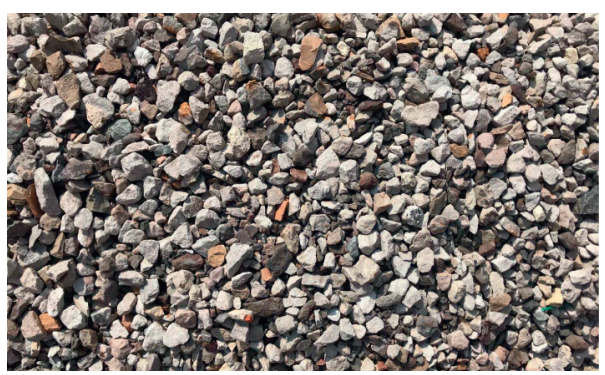

Figure 2: Coal gangue coarse aggregate.

TABLE 3: Test reference mix ratio.

\begin{tabular}{|c|c|c|c|c|c|}
\hline Group & Natural coarse aggregate $\left(\mathrm{kg} / \mathrm{m}^{3}\right)$ & Natural fine aggregate $\left(\mathrm{kg} / \mathrm{m}^{3}\right)$ & Cement $\left(\mathrm{kg} / \mathrm{m}^{3}\right)$ & Water $\left(\mathrm{kg} / \mathrm{m}^{3}\right)$ & $\mathrm{W} / \mathrm{C}$ \\
\hline C30 & 1117.9 & 685.1 & 350 & 147 & 0.42 \\
\hline $\mathrm{C} 40$ & 1118.2 & 656.8 & 380 & 144 & 0.38 \\
\hline
\end{tabular}

TABle 4: Test scheme.

\begin{tabular}{|c|c|c|c|c|c|}
\hline Group & Number & $\begin{array}{l}\text { Coarse gangue } \\
\text { coarse aggregate }\end{array}$ & $\begin{array}{l}\text { Coal gangue } \\
\text { fine aggregate }\end{array}$ & $\begin{array}{c}\text { Natural coarse } \\
\text { aggregate }\end{array}$ & $\begin{array}{l}\text { Natural fine } \\
\text { aggregate (\%) }\end{array}$ \\
\hline \multirow{4}{*}{ C30 } & NAC & 0 & 0 & $100 \%$ & 100 \\
\hline & N-SFC & 0 & $30 \%$ & $100 \%$ & 70 \\
\hline & $\mathrm{N}-\mathrm{SAC}$ & $100 \%$ & 0 & 0 & 100 \\
\hline & N-SC & $100 \%$ & $30 \%$ & 0 & 70 \\
\hline \multirow{4}{*}{ C40 } & NAC & 0 & 0 & $100 \%$ & 100 \\
\hline & N-SFC & 0 & $30 \%$ & $100 \%$ & 70 \\
\hline & N-SAC & $100 \%$ & 0 & 0 & 100 \\
\hline & N-SC & $100 \%$ & $30 \%$ & 0 & 70 \\
\hline
\end{tabular}

$100 \times 100 \times 100 \mathrm{~mm}$ were used, and each group was poured with 3 pieces. The test results were averaged and multiplied by a conversion factor of 0.95 . A WAW-1000C microcomputer-controlled electrohydraulic servo universal testing machine was used for the test. The loading speed was set at $0.5 \mathrm{MPa} / \mathrm{s}$. The test device is shown in Figure 3.
2.3.2. Drop Weight Impact Test of Coal Gangue Concrete. As shown in Figure 4, according to the concrete drop impact test method recommended by the American Concrete Association [26], the impact resistance of the specimens was measured by using a self-made drop weight impact test device. The support of the drop weight impact 


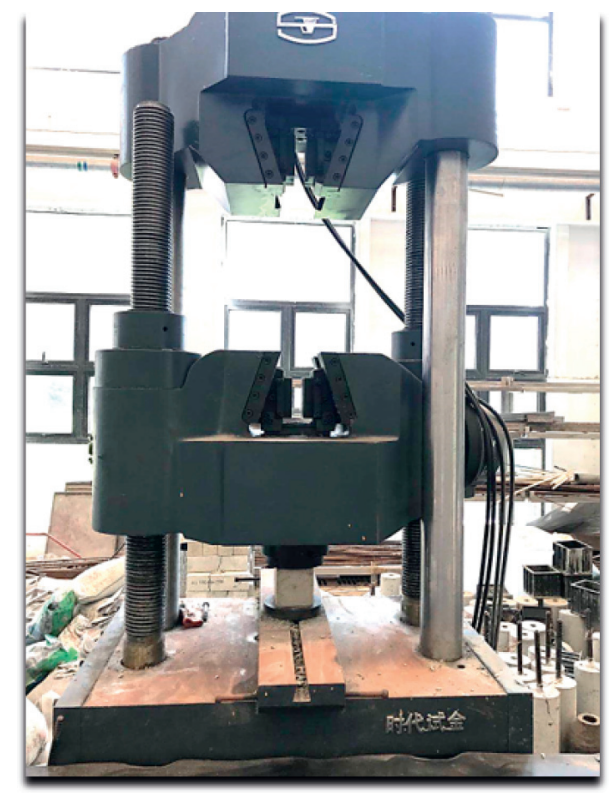

FIGURE 3: Compressive strength test equipment.

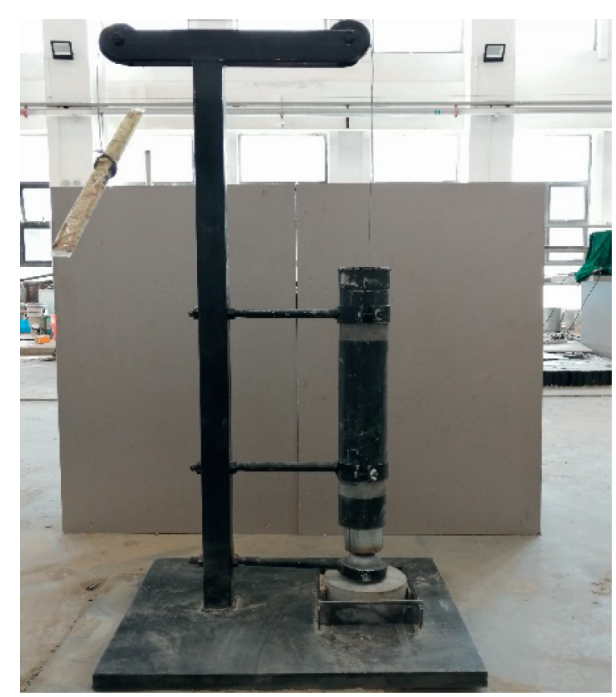

Figure 4: Drop weight impact test instrument.

test device was a horizontal rigid plate. A steel vertical cylinder was set in the test. The drop weight was lifted to the groove position set at the top of the vertical cylinder. Because the diameter of the cylinder was slightly larger than the diameter of the falling hammer, the lifting height of the falling weight could be accurately controlled. In addition, the center of the groove, the steel strand on the pulley, and the center of the test piece were connected to the three lines and were perpendicular to the upper surface of the test piece, thus ensuring that the drop point of the hammer did not deviate from the center of the test piece during the test. The drop weight smashed a force-transmitting steel ball (diameter: $63.5 \mathrm{~mm}$ ) from a certain height freely to the center of the test piece and then transmitted the impact energy to the test piece. This cycle was repeated, and the number of initial cracking impacts $(N 1)$ and complete damage impacts (N2) of the 8 test pieces was recorded. By comparing the impact times of different specimens at the same height and calculating the impact energy consumption of each group of concrete according to the relevant formula, the impact resistance of the concrete was evaluated. The drop weight impact test device included a drop weight, a force-transmitting steel ball, a vertical pipe, a fixed baffle, a pair of pulleys, a steel vertical cylinder, and a rigid support; further, a nonelastic and smooth steel strand was used as the traction line of the pulley.

After the experiment, the initial crack energy and failure energy of each group of concrete were calculated according to the following formula:

$$
W=N \cdot m g h,
$$

where $W$ stands for the impact energy, $N$ stands for the impact times corresponding to initial cracking or complete failure, $m$ stands for the weight of the drop weight $(4.5 \mathrm{~kg}), g$ stands for the acceleration of gravity $(9.8 \mathrm{~N} / \mathrm{kg})$, and $h$ stands for the impact height of the drop hammer $(457 \mathrm{~mm})$.

2.3.3. SHPB Impact Test of Coal Gangue Concrete. The dynamic impact test of SHPB was carried out with a $\Phi 75 \mathrm{~mm}$ Split Hopkinson Pressure Bar at the Impact Dynamics Laboratory of Anhui University of Science and Technology. The SHPB test device was mainly composed of an impact rod, an incident rod, a transmission rod, and an absorption rod. The data acquisition system was mainly composed of a strain gauge, a velocity measuring device, a dynamic strain gauge, waveform storage, and a software processing system $[28,32,33]$. The impact bar, incident rod, transmission rod, and absorption rod were all steel compression rods with a density of $7850 \mathrm{~kg} / \mathrm{m}^{3}$, an elastic modulus of $210 \mathrm{GPa}$, and a longitudinal wave impedance of $5190 \mathrm{~m} / \mathrm{s}$. Figures 5(a) and 5(b) show the SHPB test device and the gas pressure control and data acquisition system, respectively.

In order to satisfy the assumption of one-dimensional stress wave and stress-strain uniformity, the following measures were taken during the SHPB test:

(1) A cylinder specimen with a diameter of $35 \mathrm{~mm}$ and a length diameter ratio of 0.5 was used (as shown in Figure 6(a)).

(2) The sample was ground to ensure that the surface unevenness of the sample was controlled within $0.05 \mathrm{~mm}$, and the unevenness of both ends was controlled within $0.03 \mathrm{~mm}$ (as shown in Figure 6(b)).

(3) A certain thickness of ultralight clay was adsorbed at the front end of the incident rod (as shown in Figure 6(c)).

(4) Before the experiment, it was ensured that the specimen and the compression bar were coaxial, and in order to reduce the friction between the specimen and the pressure bar, vaseline was applied on both ends of the sample.

The specific test process mainly included the following steps: 


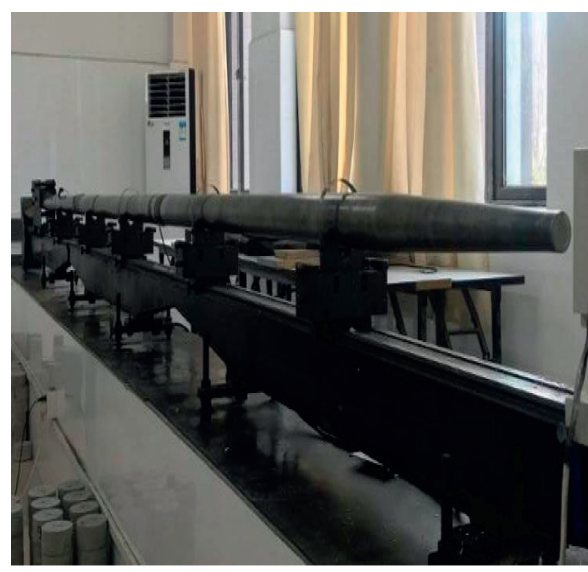

(a)

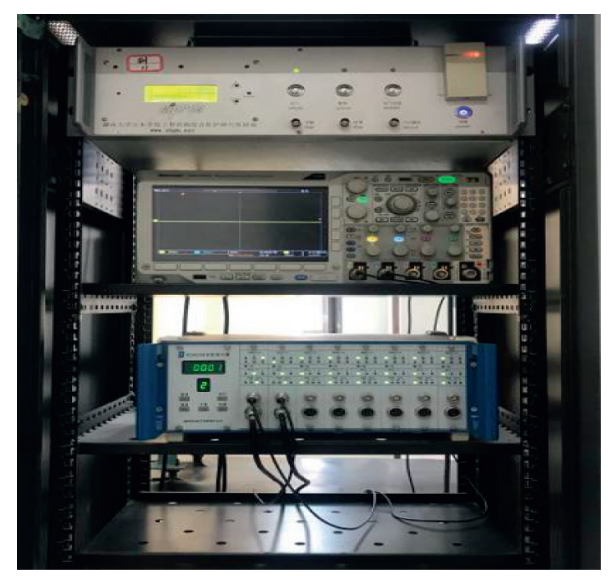

(b)

FIgURE 5: The SHPB experimental equipment. (a) SHPB test device. (b) Gas pressure control and data acquisition system.

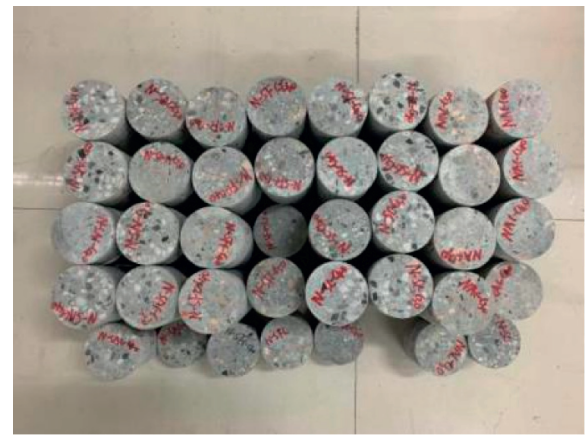

(a)

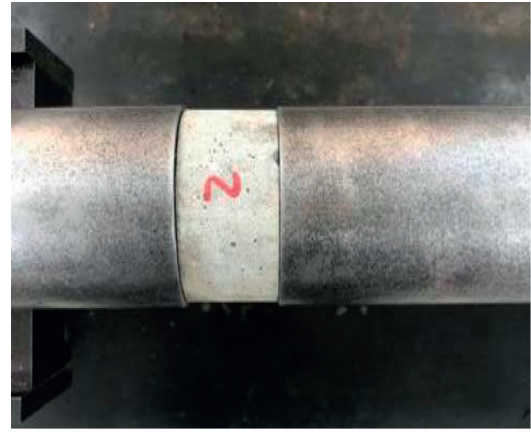

(b)

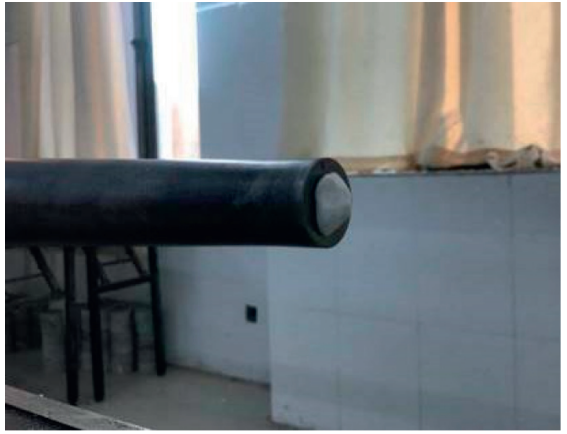

(c)

FIGURE 6: SHPB test specimen. (a) Specimen. (b) Specimen installation. (c) Superlight clay as shaper.

(1) Experiment preparation: before the experiment, we checked whether the SHPB experiment device and all equipment of the whole system were in normal operation. The positions of the impact bar, incident bar, and transmission rod were adjusted to ensure that the central axis of the three rods coincided. The instrument was tested to adjust the parameter values, and then the trigger voltage, bridge voltage, gain, and other parameters were set.

(2) Specimen installation: in order to reduce the friction between the specimen and the pressure bar, vaseline was applied on the end faces of the test piece and the pressure bar, and then the specimen was pressed so that it was firmly clamped between the incident rod and the transmission rod. Next, the specimen was wrapped with a towel to prevent fragments from flying away. Finally, the ultralight clay was bonded to the front end of the incident rod.

(3) Formal experiment: the inflation switch was started, the acquisition switch was turned on, and when it rose to the set gas pressure, the impact rod was activated and the impact test was carried out.

(4) The data were saved and the specimen damage was recorded.

\section{Experimental Results and Discussion}

3.1. Compressive Strength of Coal Gangue Concrete. The failure cross section and compressive strength test results of coal gangue concrete are shown in Figure 7.

As shown in Figure 7, comparing the failure modes of each group of concrete test blocks, it was found that the failure modes of coal gangue concrete and ordinary concrete were similar. After the failure of each group of specimens, they all appeared as "reversely connected quadrangular pyramids," but each exhibited different failure characteristics. For the N-SFC group, it was the destruction of the cement mortar and the interface between some natural coarse aggregates and cement mortar. The natural aggregate in the concrete was relatively complete, and the fractured section was uneven. The combination of coarse aggregate and cement mortar was one of a "weak" mortar wrapped around a "strong" aggregate. For the N-SAC and N-SC groups, not only were there cement mortar damage and separation failure between the coal gangue coarse aggregate and the mortar, but also the coal gangue coarse aggregate itself was broken, so the damaged section was relatively flat. The combination of gangue coarse aggregate and cement mortar was a "strong" mortar wrapped around a "weak" aggregate. 


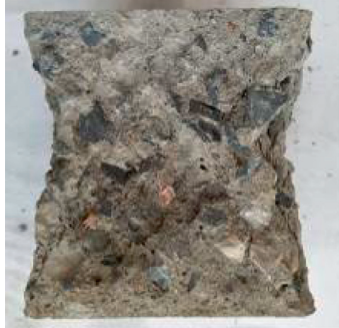

(a)

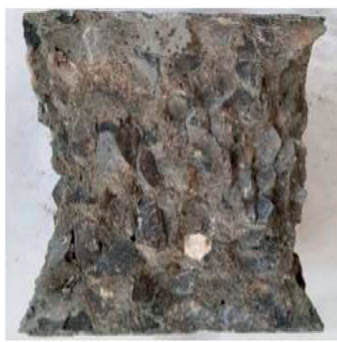

(e)

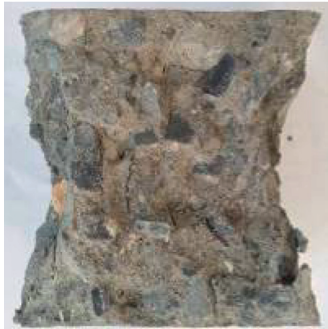

(b)

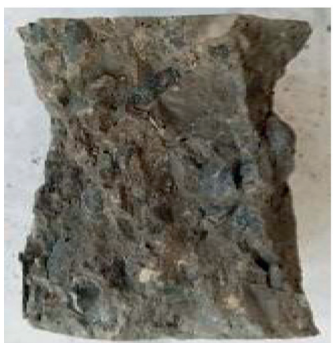

(f)

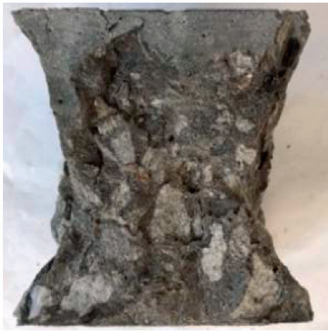

(c)

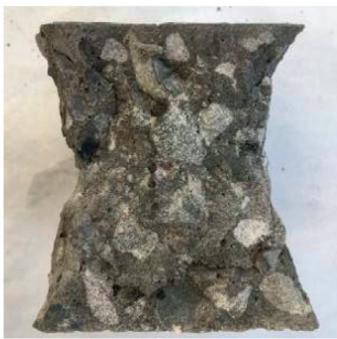

(g)

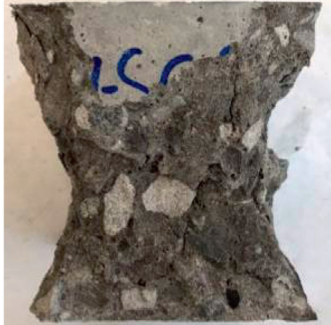

(d)

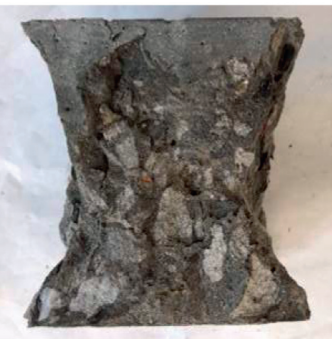

(h)

Figure 7: Concrete failure section. (a) NAC-C30. (b) N-SFC-C30. (c) N-SAC-C30. (d) N-SC-C30. (e) NAC-C40. (f) N-SFC-C40. (g) NSAC-C40. (h) N-SC-C40.

Comparing the compressive strengths of N-SFC, N-SAC, N-SC, and NAC under the two preparation strengths in Table 5, it was found that the 3-day strengths all reached more than $50 \%$ of the 28 -day strength, the 7 -day strengths all reached more than $70 \%$ of the 28 -day strength, the 28 -day strengths all reached the design strength requirements, the 60 -day strength increased by $5-10 \%$ compared with the 28 day strength, and the 90 -day intensity was $10-18 \%$ higher than the 28-day intensity. This shows that the compressive strength of coal gangue concrete with age is basically the same as that of ordinary concrete under the same design strength. The ultimate compressive strength of coal gangue concrete increases with age, but the growth rate becomes increasingly slower.

Comparing the measured strength and preparation strength of the doped coal gangue concrete in Table 5, under the C30 preparation strength, it was found that the 28-day strength of the concrete doped with coal gangue was greater than $38.23 \mathrm{MPa}$ [29], which meets the requirements of the concrete preparation strength. Under the C40 preparation strength, the 28-day strength of the concrete single-doped with coal gangue was greater than $48.23 \mathrm{MPa}$ [29], which meets the requirements of concrete preparation strength. Therefore, it can be concluded that the use of coal gangue to replace natural coarse and fine aggregates in concrete can work to completely prepare C30 and C40 concrete that meets the requirements and realizes the resource utilization of coal gangue.

Figure 8 shows the destruction surface of different groups at C30 preparation strength, and greater difference appeared at the destruction surface. For the NAC and $\mathrm{N}-\mathrm{SFC}$, it was observed that the destruction surface is rough. And for the N-SAC and N-SC, the destruction surface is smooth, especially for the N-SAC. The difference in the destruction surface can be explained by the lower strength of coal gangue and the better "gangue-cement" contacting surface. In the traditional concrete analysis, the strength characteristic of the internal structure of concrete in descending order is coarse aggregate, mortar, and contacting surface between coarse aggregate and mortar. When the coal gangue was used to replace the fine aggregate, the lower strength of the coal gangue will not change the strength characteristic of the internal structure of concrete. While the strength characteristics of each component in concrete may change when the concrete is single-doped with coarse aggregate or codoped with coal gangue coarse and fine aggregate, which shows that the strength of the bearing skeleton (coarse aggregate) decreases and the contact surface (contact surface between coarse aggregate and mortar) increases, which will lead to the shear surface of concrete not develop along the interface between aggregate and mortar, but along the interior of coal gangue. Therefore, the shear plane of concrete is relatively flat, especially when the coarse aggregate of concrete is coal gangue.

3.2. Impact Resistance of Coal Gangue Concrete. The drop weight impact test results of coal gangue concrete are shown in Figures 8-10.

It can be seen from Figures 9 and 10 that the failure morphology of the N-SFC, N-SAC, and N-SC specimens under the impact load under the two preparation strengths is similar to that of ordinary concrete NAC. The phenomenon of "destruction once cracked" occurred, showing obvious brittle cracking.

It can be seen from Figure 11 that the influence of singledoped and codoped coal gangue coarse and fine aggregates on the amount of concrete initial cracking and final cracking was roughly the same under different preparation strengths, and the regularity was relatively strong. With single-doped 
TABLE 5: Compressive strength of concrete after conversion.

\begin{tabular}{ccccccccccc}
\hline \multirow{2}{*}{ Group } & \multirow{2}{*}{ Numbering } & \multicolumn{4}{c}{ Compressive strength $(\mathrm{MPa})$} & \multicolumn{4}{c}{ Compressive strength growth rate } \\
& & 3 days & 7 days & 28 days & 60 days & 90 days & 3-7 days & $7-28$ days & $28-60$ days & $60-90$ days \\
\hline \multirow{3}{*}{ C30 } & NAC & 26.45 & 31.50 & 39.94 & 43.42 & 46.42 & 0.191 & 0.268 & 0.087 \\
& N-SFC & 24.34 & 31.08 & 44.67 & 49.10 & 52.94 & 0.277 & 0.437 & 0.099 \\
& N-SAC & 23.30 & 31.12 & 39.07 & 42.47 & 43.91 & 0.336 & 0.255 & 0.087 \\
& N-SC & 22.39 & 31.35 & 41.83 & 45.67 & 47.43 & 0.400 & 0.334 & 0.092 & 0.078 \\
\multirow{4}{*}{ C40 } & NAC & 36.14 & 41.87 & 48.62 & 53.04 & 55.92 & 0.159 & 0.161 & 0.091 \\
& N-SFC & 31.29 & 40.32 & 54.42 & 59.42 & 60.96 & 0.289 & 0.35 & 0.092 & 0.039 \\
& N-SAC & 29.46 & 41.74 & 47.34 & 50.11 & 52.50 & 0.417 & 0.134 & 0.059 & 0.034 \\
& N-SC & 27.89 & 42.00 & 49.79 & 53.65 & 55.69 & 0.506 & 0.185 & 0.078 \\
\hline
\end{tabular}

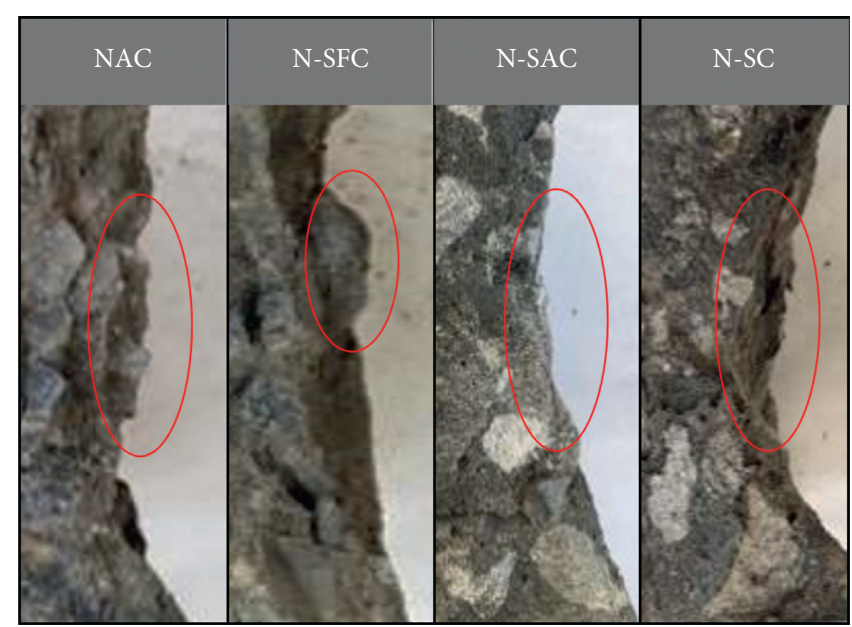

FIGURE 8: Destruction surface.

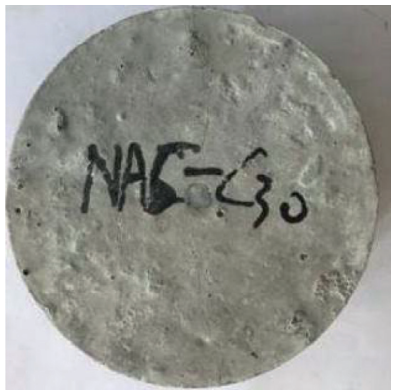

(a)

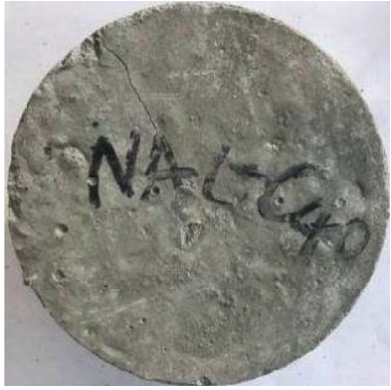

(e)

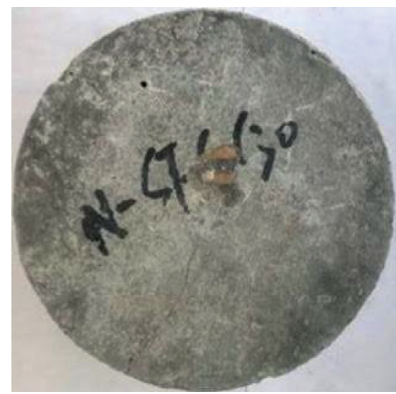

(b)

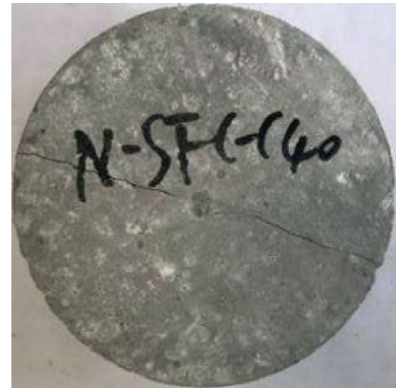

(f)

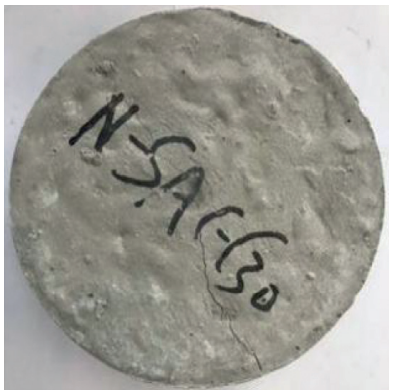

(c)

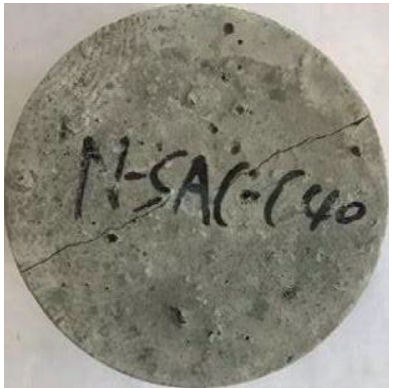

$(\mathrm{g})$

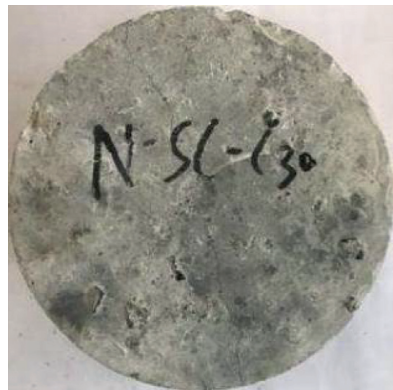

(d)

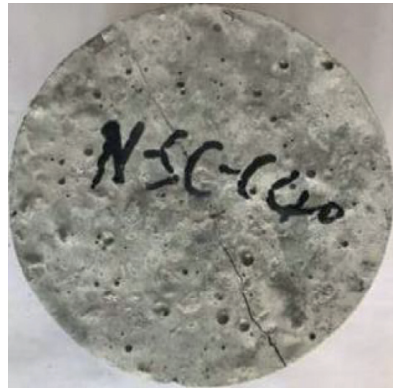

(h)

FIGURE 9: Initial cracking state of concrete. (a) NAC-C30. (b) N-SFC-C30. (c) N-SAC-C30. (d) N-SC-C30. (e) NAC-C40. (f) N-SFC-C40. (g) N-SAC-C40. (h) N-SC-C40. 


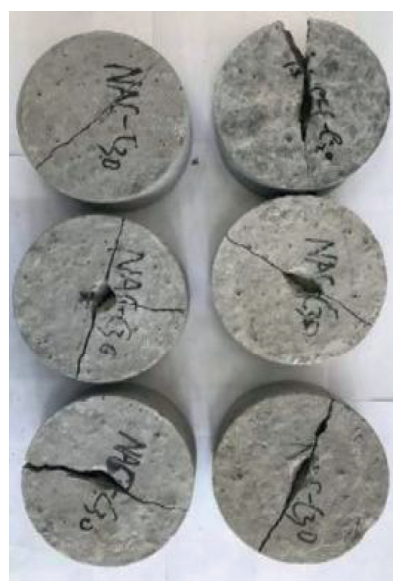

(a)

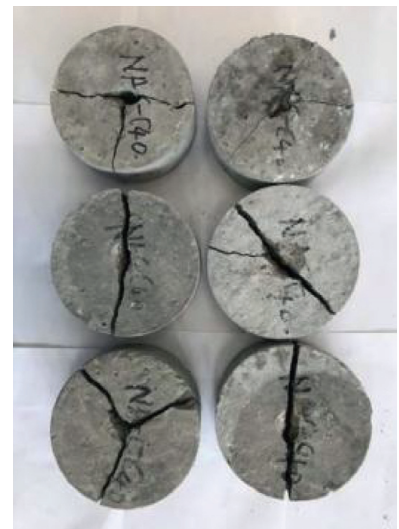

(e)

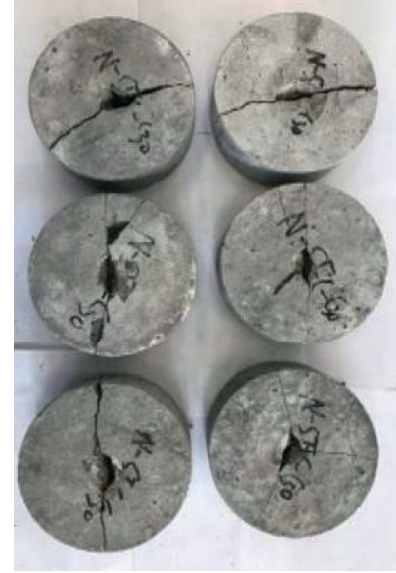

(b)

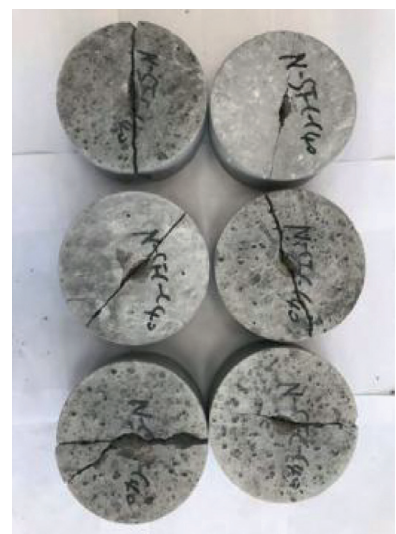

(f)

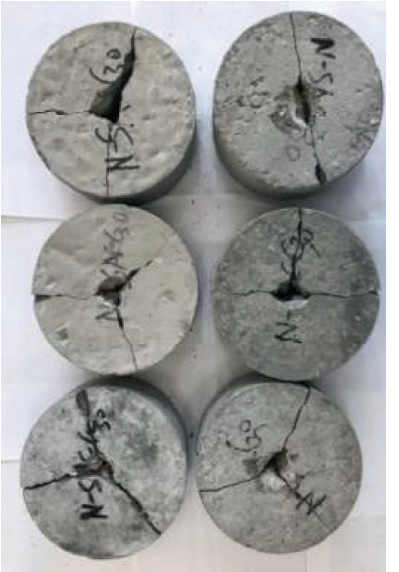

(c)

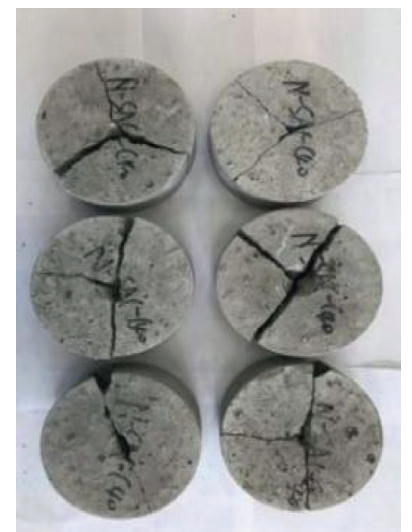

(g)

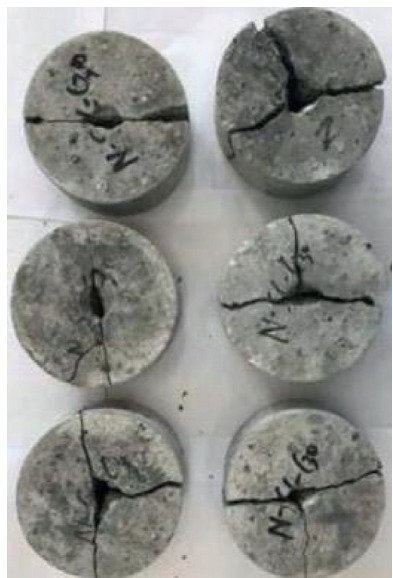

(d)

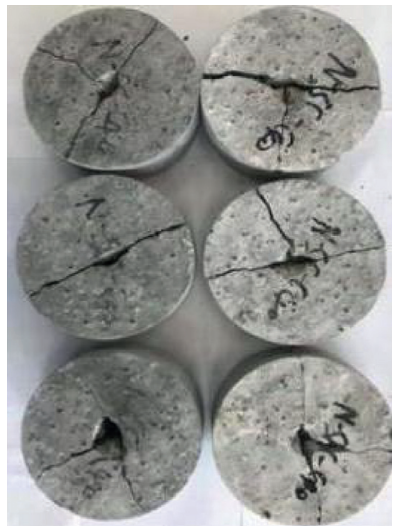

(h)

FIgURe 10: Final cracking state of concrete. (a) NAC-C30. (b) N-SFC-C30. (c) N-SAC-C30. (d) N-SC-C30. (e) NAC-C40. (f) N-SFC-C40. (g) N-SAC-C40. (h) N-SC-C40.

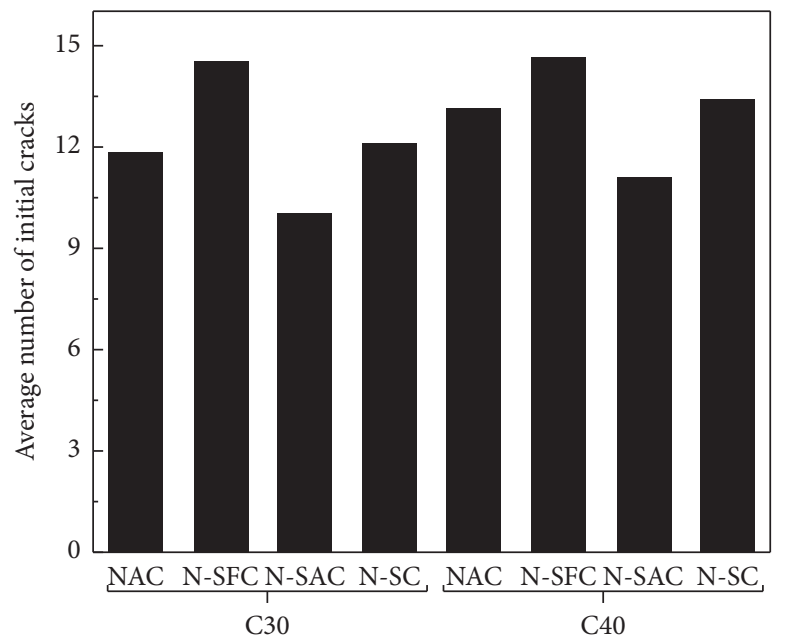

(a)

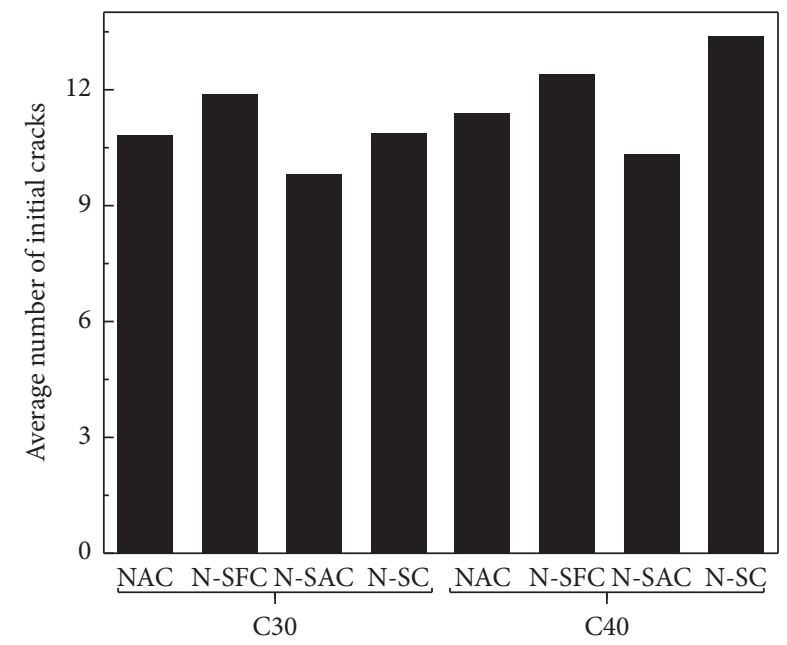

(b)

Figure 11: Comparison of impact resistance times of coal gangue concrete. (a) Initial cracking. (b) Final cracking.

coal gangue fine aggregate, the average impact resistance of the initial and final cracking of the two kinds of preparation strengths for coal gangue fine aggregate concrete was greater than that of ordinary concrete. With single-doped coal gangue coarse aggregate, the average impact resistance of the initial and final cracking of the two kinds of preparation 
strengths for coal gangue coarse aggregate concrete was less than that of ordinary concrete. With codoped coal gangue coarse and fine aggregates, the average impact resistance of the initial cracking of the two kinds of preparation strengths for coal gangue concrete was greater than that of ordinary concrete, while the final cracking was equal to that of ordinary concrete. The results show that the single-doped coal gangue fine aggregate can increase the average impact resistance of the initial and final cracking of the concrete, and the single-doped coal gangue coarse aggregate can reduce the average impact resistance of the initial and final cracking of concrete. On the basis of doping coal gangue coarse aggregate, adding the appropriate amount of coal gangue fine aggregate can increase the impact resistance of the initial and final cracking of coal gangue concrete.

When the preparation strength was $\mathrm{C} 30$ and $\mathrm{C} 40$, the initial cracking impact energy of the concrete single-doped with coal gangue fine aggregate was 292.2 and $294.2 \mathrm{~J}$, the final cracking impact energy was 239.8 and $249.9 \mathrm{~J}$ (the definition of final cracking impact energy is the energy from the initial cracking impact to the final crack impact), and the average failure energy was 266 and $272.1 \mathrm{~J}$, respectively. Compared with ordinary concrete (the initial, final, and average cracking impact energy of C30 and C40 were 237.8, $217.7,227.8,264.0,229.8$, and $246.9 \mathrm{~J}$, resp.), the impact energy of the initial and final cracking of N-SAC-C30 and N-SAC-C40 increased by $22.9 \%, 10.2 \%, 11.4 \%$, and $8.7 \%$, and the average failure energy of N-SAC-C 30 and N-SACC40 increased by $16.8 \%$ and $10.2 \%$, respectively.

The initial cracking impact energy of the concrete singledoped with coal gangue coarse aggregate of the C30 and C40 concrete was 201.5 and $223.7 \mathrm{~J}$, the final cracking impact energy was 197.5 and $207.6 \mathrm{~J}$, and the average failure energy was 199.5 and $215.7 \mathrm{~J}$, respectively. Compared with ordinary concrete, the impact energy of initial and final cracking of N-SFC-C30 and N-SFC-C40 decreased by $15.2 \%, 9.3 \%$, $15.4 \%$, and $9.7 \%$, and the average failure energy of N-SFCC30 and N-SFC-C40 decreased by $12.4 \%$ and $12.6 \%$, respectively.

The initial cracking impact energy of the concrete codoped with coal gangue coarse and fine aggregates was 243.9 and $270.1 \mathrm{~J}$, the final cracking impact energy was 219.7 and $229.8 \mathrm{~J}$, and the average failure energy was 231.8 and $250 \mathrm{~J}$, respectively. Compared with ordinary concrete, the impact energy of initial cracking of C30 and C40 concrete increased by $2.6 \%$ and $2.3 \%$, the impact energy of final cracking of C30 and C40 concrete increased by $0.9 \%$ and $0.1 \%$, and the average failure energy of N-SC-C 30 and N-SCC40 increased by $1.7 \%$ and $1.3 \%$, respectively. Compared with the concrete single-doped with coal gangue aggregate, the impact energy of initial and final cracking of N-SC-C30 and N-SC-C40 increased by $21 \%, 11.1 \%, 20.7 \%$, and $10.7 \%$, and the average failure energy of N-SC-C 30 and N-SC-C40 concrete increased by $16.2 \%$ and $15.9 \%$, respectively.

Based on the above analysis, it can be found that the impact resistance of concrete single-doped with coal gangue fine aggregate is higher than the concrete single-doped with coal gangue coarse aggregate. This is related to the porous structure and low strength of coal gangue. As shown in
Figure 12, by observing the SEM pictures of coal gangue and limestone flat section, it can be found that the microstructure of coal gangue is porous, while the microstructure of limestone is dense; there is a significant difference between the two. It should be noted that, in the concrete structure system, the coarse aggregate is generally used as the main bearing structure, while the fine aggregate and cementitious material are generally used as the force transmission structure. In the concrete single-doped with coal gangue fine aggregate, the coarse interface of coal gangue fine aggregate makes the cementitious material and concrete fine aggregate form a good force transmission structure. At this time, the lower strength of coal gangue has little influence on the mechanical structure of concrete, so the impact strength of concrete single-doped with coal gangue fine aggregate increases. In the concrete single-doped with coal gangue coarse aggregate, as the main bearing structure, the low strength of coal gangue weakens the mechanical structure of concrete. At this time, the good contact characteristics of coal gangue and cementitious materials have little influence on the mechanical structure of concrete, so the impact strength of concrete single-doped with coal gangue coarse aggregate decreases.

\subsection{Dynamic Compressive Strength of Coal Gangue Concrete.} The average dynamic compressive strengths of coal gangue concrete under different gas pressures are shown in Figure 13.

As shown in Figure 13, the dynamic compressive strength growth law of coal gangue concrete and ordinary concrete is basically the same. Compared with the static compressive strength, the dynamic compressive strength of each group of concrete specimens under the two kinds of preparation strengths has different degrees of improvement, and the dynamic compressive strength also increases with the increase of impact gas pressure. Comparing the dynamic compressive strength under $0.4,0.5,0.6$, and $0.7 \mathrm{MPa}$ gas pressure with the static compressive strength, under the design strength of C30, the ordinary concrete increased by $11.2 \%, 16.5 \%, 25.1 \%$, and $31.3 \%$, respectively; the concrete single-doped with coal gangue fine aggregate increased by $9.8 \%, 17.0 \%, 23.0 \%$, and $30.4 \%$, respectively; the concrete single-doped with coal gangue coarse aggregate increased by $10.6 \%, 13.5 \%, 22.2 \%$, and $28.1 \%$, respectively; and the concrete codoped with coal gangue coarse and fine aggregates increased by $9.1 \%, 14.7 \%, 21.4 \%$, and $30.4 \%$, respectively. Under the design strength of $\mathrm{C} 40$, the ordinary concrete increased by $13.5 \%, 21.3 \%, 25.5 \%$, and $32.2 \%$, respectively; the concrete single-doped with coal gangue fine aggregate increased by $8.3 \%, 13.7 \%, 20.5 \%$, and $30.1 \%$, respectively; the concrete single-doped with coal gangue coarse aggregate increased by $13.2 \%, 17.2 \%, 20.8 \%$, and $25.8 \%$, respectively; and the concrete codoped with coal gangue coarse and fine aggregates increased by $11.0 \%$, $18.0 \%, 22.3 \%$, and $26.1 \%$, respectively.

Figure 14 shows the failure morphology of different types of concrete specimens under different impact pressures. Under 0.4 MPa impact gas pressure, different numbers 


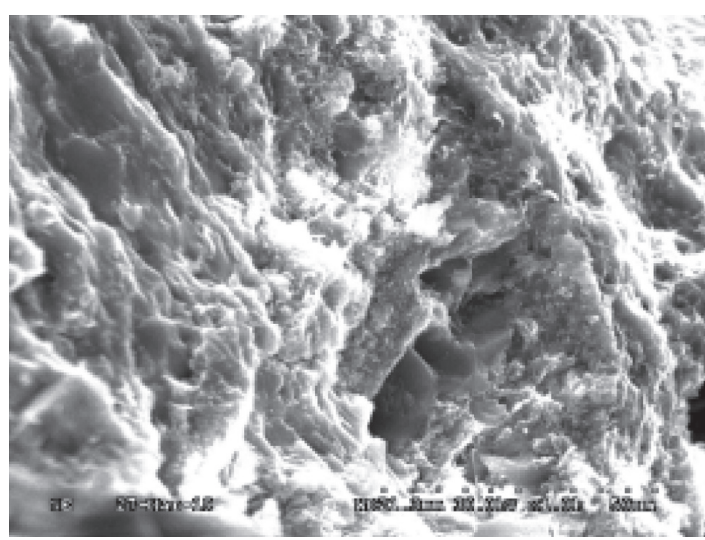

(a)

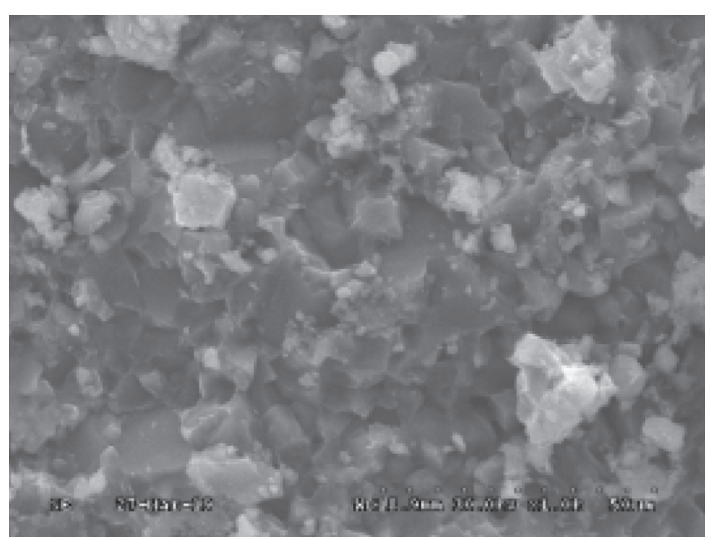

(b)

Figure 12: SEM image of coal gangue and limestone. (a) Microstructure of coal gangue. (b) Microstructure of gravels.

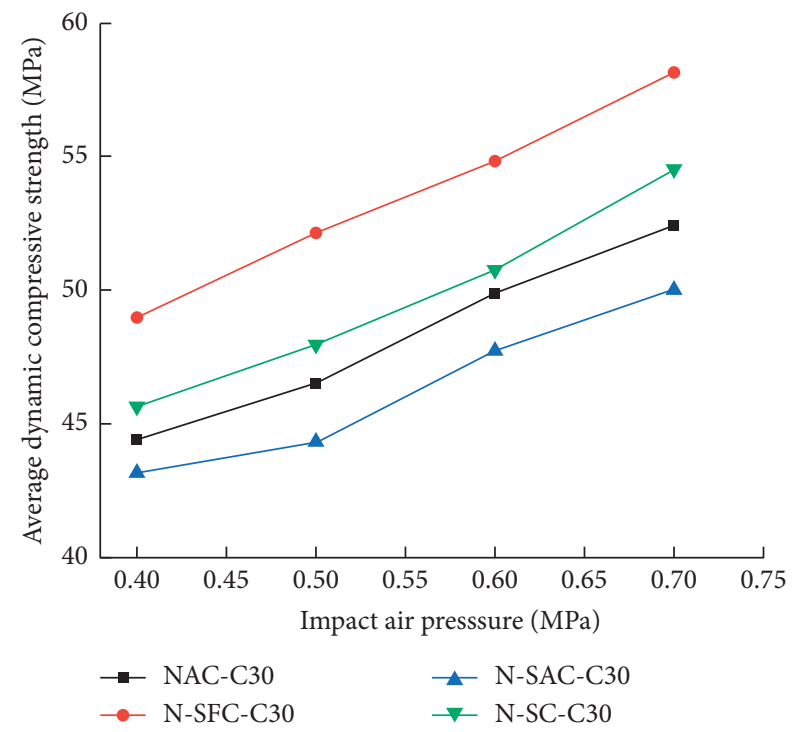

(a)

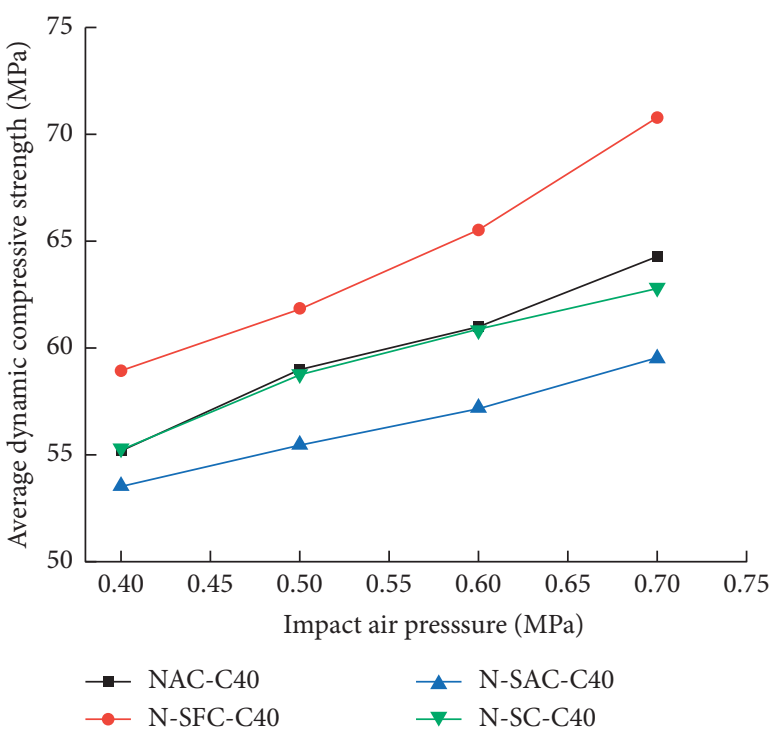

(b)

FIgURE 13: Coal gangue concrete destruction characteristics under different gas pressures. (a) C30 groups. (b) C40 groups.

and widths of cracks appeared on the surface of each group of specimens with two kinds of preparation strengths, and the specimens were relatively complete when they were destroyed. With the increase of impact gas pressure, the specimens became more and more broken. When the impact gas pressure was further increased to $0.7 \mathrm{MPa}$, the concrete specimens of each group were almost completely broken.

It can be seen from Figure 15 that the average particle size of the fragmentation of each group of specimens decreased with the increase of impact gas pressure. When the impact gas pressure was $0.4 \mathrm{MPa}$, each group of specimens of the two kinds of preparation strengths was relatively complete. When the impact gas pressure was $0.5 \mathrm{MPa}$, the order of the average particle size of the crushing block was $\mathrm{N}-\mathrm{SFC}>\mathrm{N}-\mathrm{SC}>\mathrm{N}-\mathrm{SAC}>\mathrm{NAC}$ when the preparation strength was $\mathrm{C} 30$, and the order of the average particle size of the crushing block was N-SFC $>\mathrm{N}-\mathrm{SC}>\mathrm{NAC}>\mathrm{N}-\mathrm{SAC}$ when the preparation strength was $\mathrm{C} 40$. When the impact gas pressure was $0.6 \mathrm{MPa}$, the order of the average particle size of the crushing block was N-SFC $>\mathrm{N}-\mathrm{SC}>\mathrm{N}$ $\mathrm{SAC}>\mathrm{NAC}$ when the preparation strength was $\mathrm{C} 30$, and the order of the average particle size of the crushing block was $\mathrm{N}-\mathrm{SFC}>\mathrm{NAC}>\mathrm{N}-\mathrm{SC}>\mathrm{N}-\mathrm{SAC}$ when the preparation strength was $\mathrm{C} 40$. When the impact gas pressure was $0.7 \mathrm{MPa}$, the order of the average particle size of the crushing block was N-SFC $>\mathrm{NAC}>\mathrm{N}-\mathrm{SC}>\mathrm{N}-\mathrm{SAC}$ when the preparation strength was $\mathrm{C} 30$, and the order of the average particle size of the crushing block was N-SFC $>$ NAC $>$ N$\mathrm{SC}>\mathrm{N}$-SAC when the preparation strength was C40. In summary, under the impact load, the average particle size of the single-doped coal gangue fine aggregate concrete specimen was generally higher than that of ordinary concrete, and the average particle size of the single-doped coal gangue coarse aggregate concrete specimen was generally lower than that of ordinary concrete, while the average particle size of the codoped coal gangue coarse and fine 


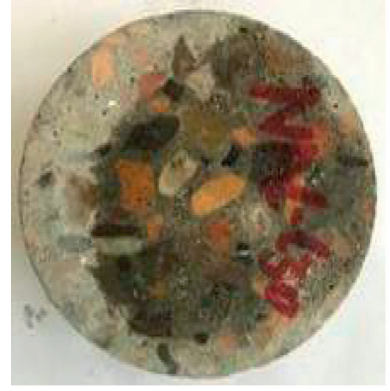

(a1) NAC-C30-0.4 MPa

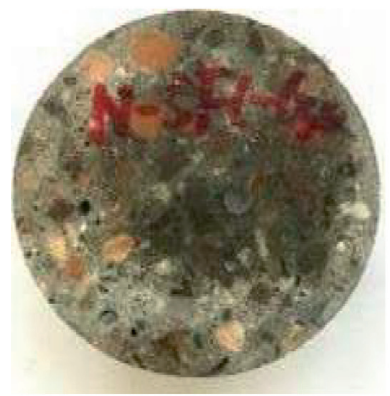

(b1) N-SFC-C30-0.4 MPa

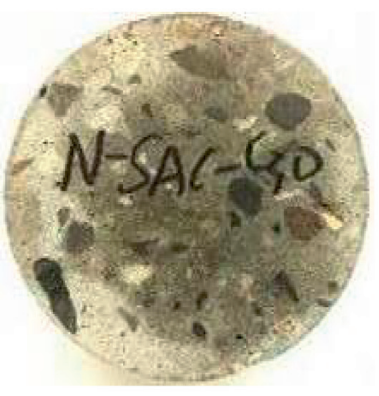

(c1) N-SAC-C30-0.4 MPa

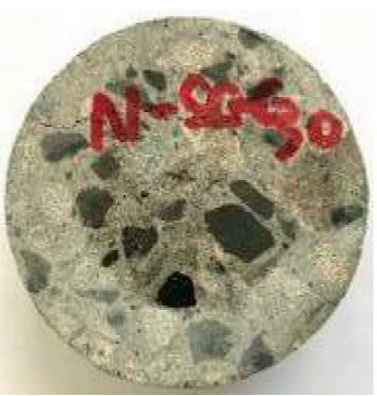

(d1) N-SC-C30-0.4 MPa

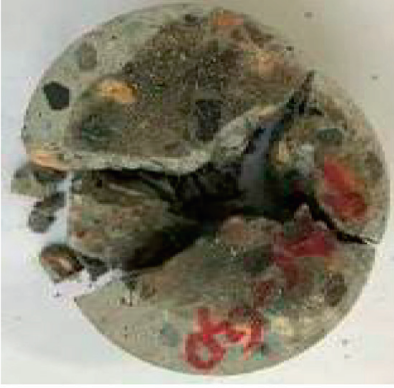

(a2) NAC-C30-0.5 MPa

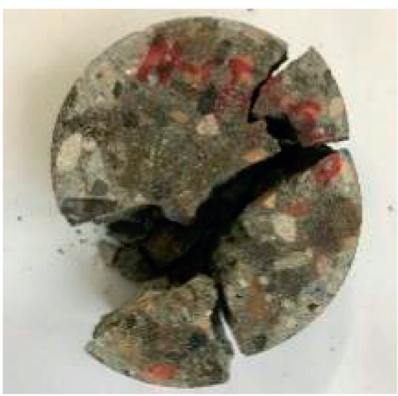

(b2) N-SFC-C30-0.5 MPa

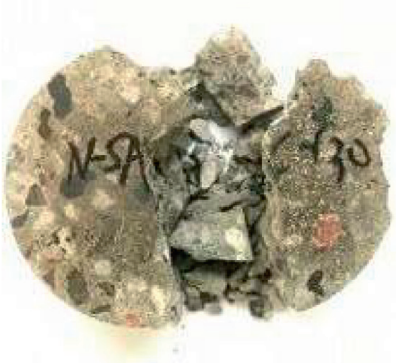

(c2) N-SAC-C30-0.5 MPa

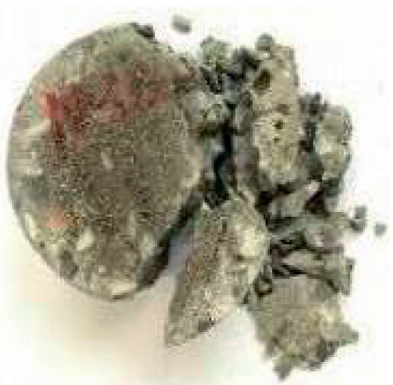

(d2) N-SC-C30-0.5 MPa

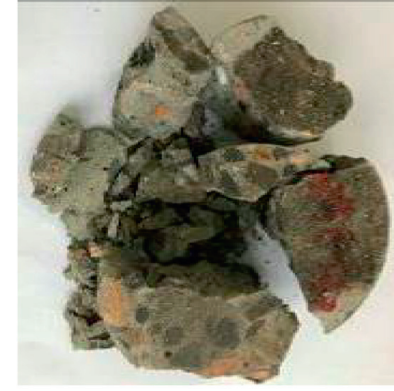

(a3) NAC-C30-0.6 MPa

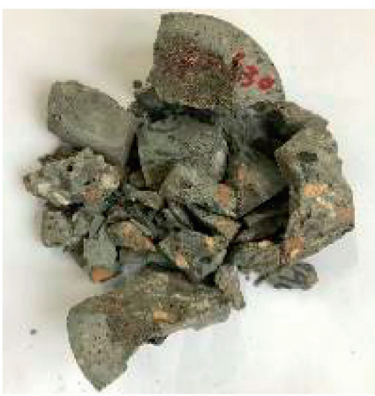

(b3) N-SFC-C30-0.6 MPa

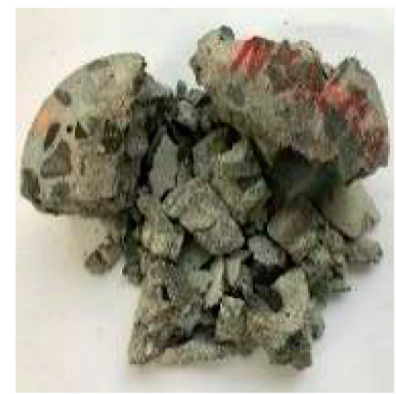

(c3) N-SAC-C30-0.6 MPa

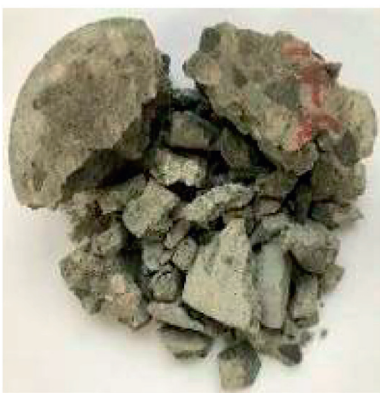

(d3) N-SC-C30-0.6 MPa

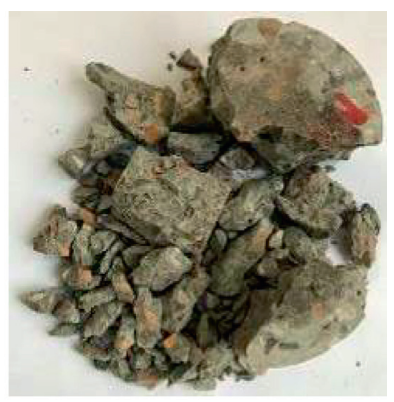

(a4) NAC-C30-0.7 MPa

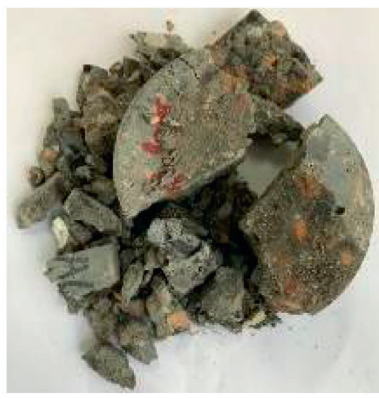

(b4) N-SFC-C30-0.7 MPa

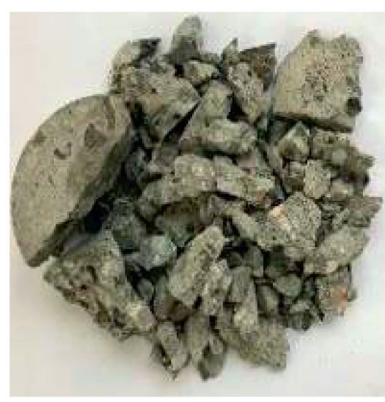

(c4) N-SAC-C30-0.7 MPa

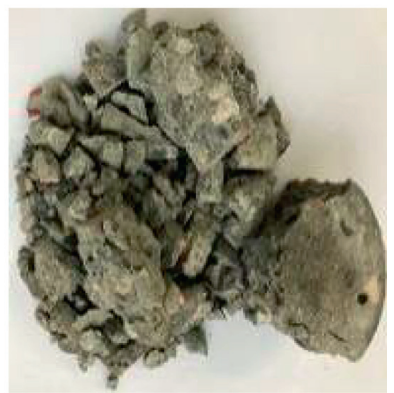

(d4) N-SC-C30-0.7 MPa

FIGURE 14: Continued. 


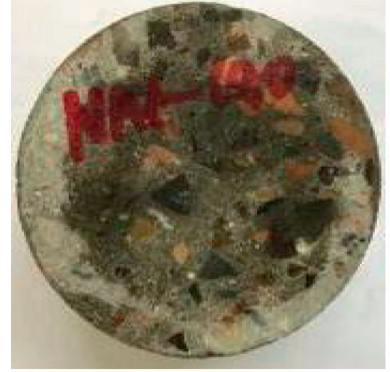

(e1) NAC-C40-0.4 MPa

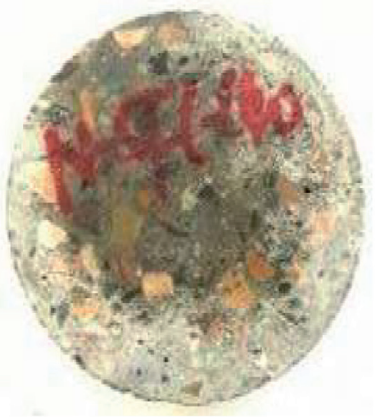

(f1) N-SFC-C40-0.4 MPa

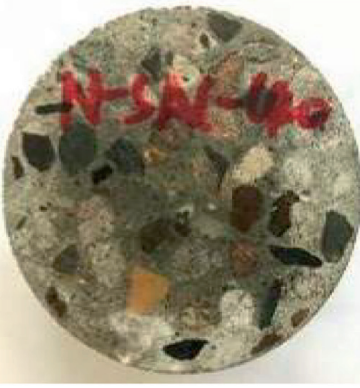

(g1) N-SAC-C40-0.4 MPa

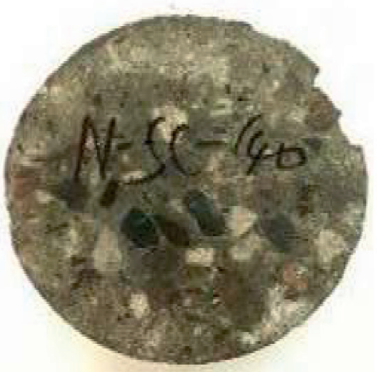

(h1) N-SC-C40-0.4 MPa

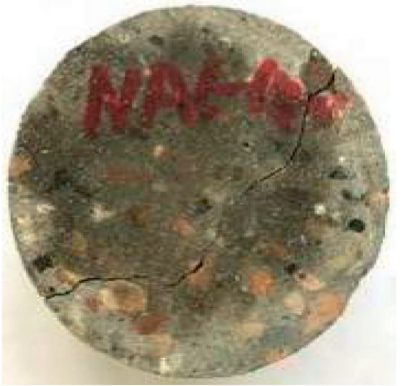

(e2) NAC-C40-0.5 MPa

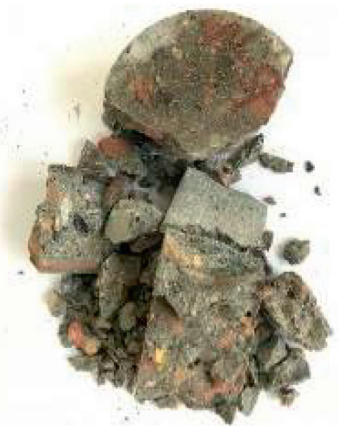

(f2) N-SFC-C40-0.5 MPa

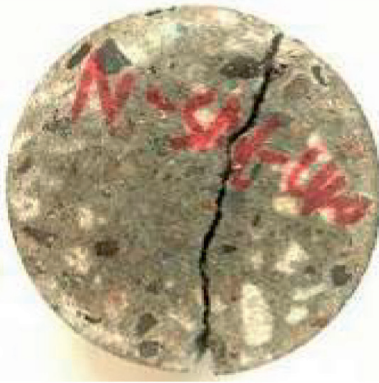

(g2) N-SAC-C40-0.5 MPa

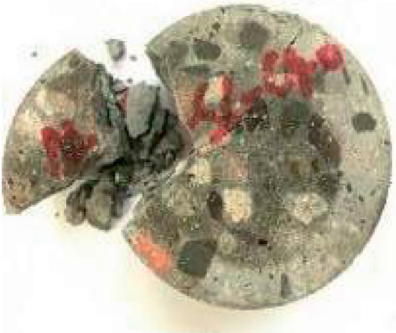

(h2) N-SC-C40-0.5 MPa

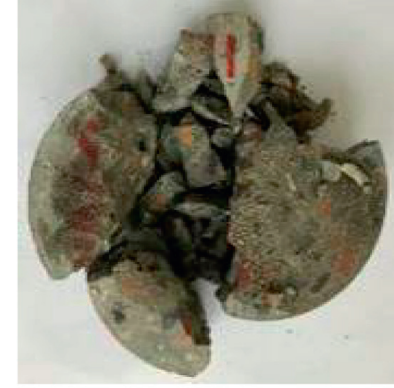

(e3) NAC-C40-0.6 MPa

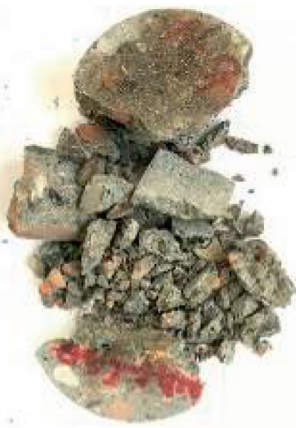

(f3) N-SFC-C40-0.6 MPa

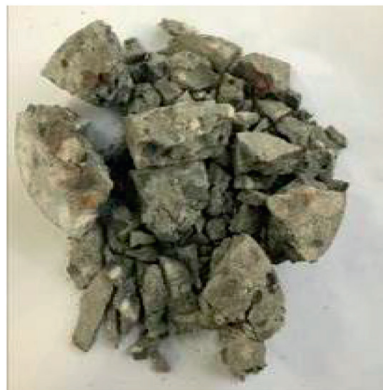

(g3) N-SAC-C40-0.6 MPa

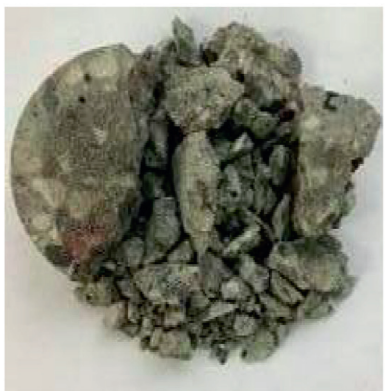

(h3) N-SC-C40-0.6 MPa

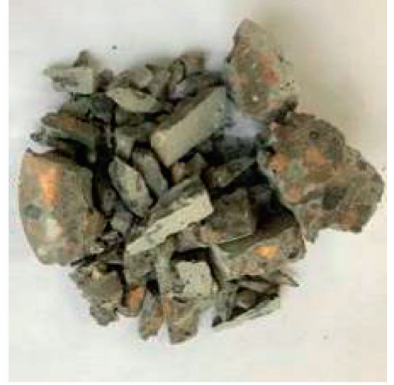

(e4) NAC-C40-0.7 MPa

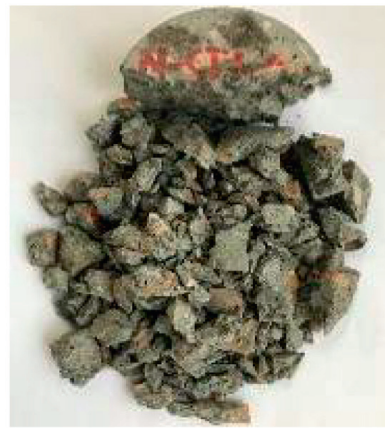

(f4) N-SFC-C40-0.7 MPa

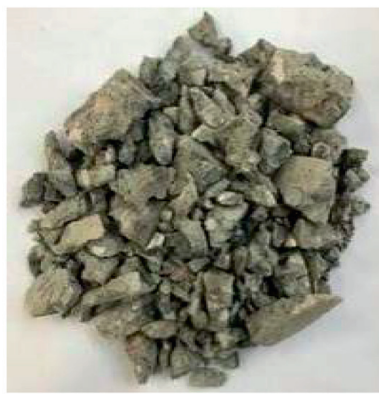

(g4) N-SAC-C40-0.7 MPa

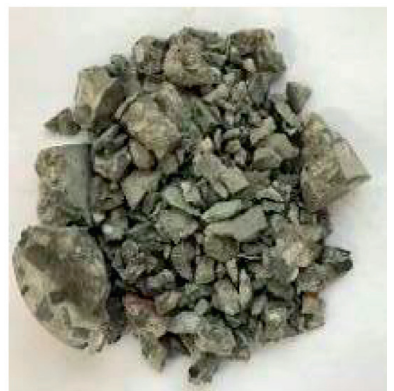

(h4) N-SC-C40-0.7 MPa

FIGURE 14: Impact specimen after crushing.

aggregate concrete specimen was larger than that of the single-doped coal gangue coarse aggregate concrete. The coal gangue fine aggregate can inhibit the expansion of cracks in concrete to a certain extent so that the concrete has good integrity when damaged.

Existing studies have shown that the distribution and evolution of many irregular pores, cracks, and other mesodefects in concrete materials satisfy statistically self-similar characteristics. The impact damage of concrete is a phenomenon in which these damage defects in the material are continuously generated and expanded under the action of dynamic impact load, eventually leading to the nonlinear damage of the concrete material. Therefore, the fractal theory was used to analyze the fragment size distribution of concrete after impact failure. 


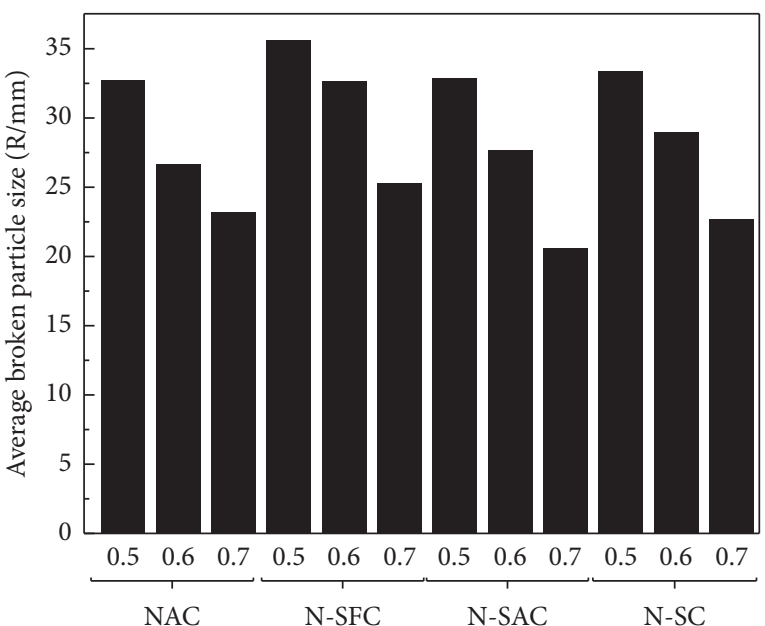

(a)

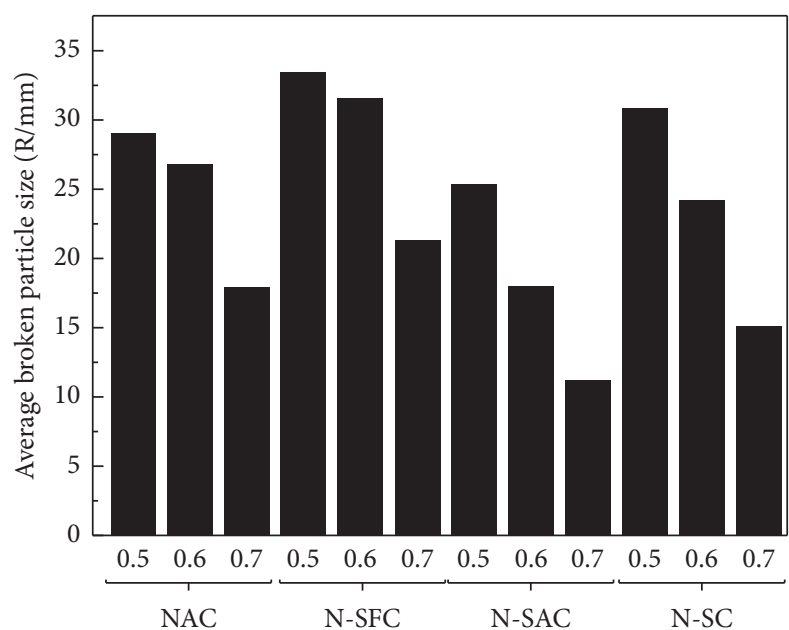

(b)

FIGURE 15: Average particle size after SHPB impact. (a) C30 groups. (b) C40 groups.

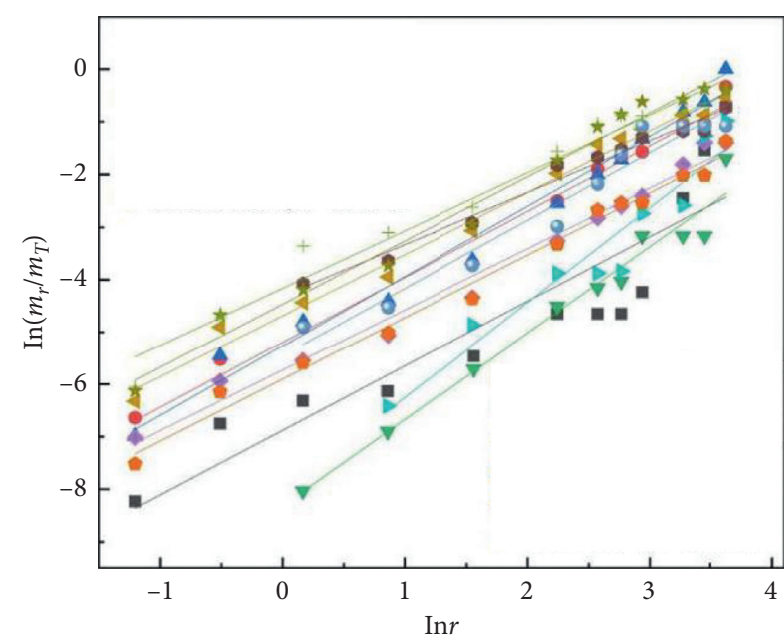

- NAC-C $30-2, R^{2}=0.81573$ N-SAC-C $30-2, R^{2}=0.91167$

- NAC-C $30-3, R^{2}=0.98603$ N-SAC-C $30-3, R^{2}=0.97753$

॥ NAC-C $30-4, R^{2}=0.98046 \star$ N-SAC-C $30-4, R^{2}=0.98104$

$\checkmark$ NSFC-C $30-2, R^{2}=0.96756$ N-SC-C30-2, $R^{2}=0.98817$

- NSFC-C $30-3, R^{2}=0.98279$ - N-SC-C30-3, $R^{2}=0.94921$

4 NSFC-C30-4, $R^{2}=0.98746+$ N-SC-C30-4, $R^{2}=0.96616$

(a)

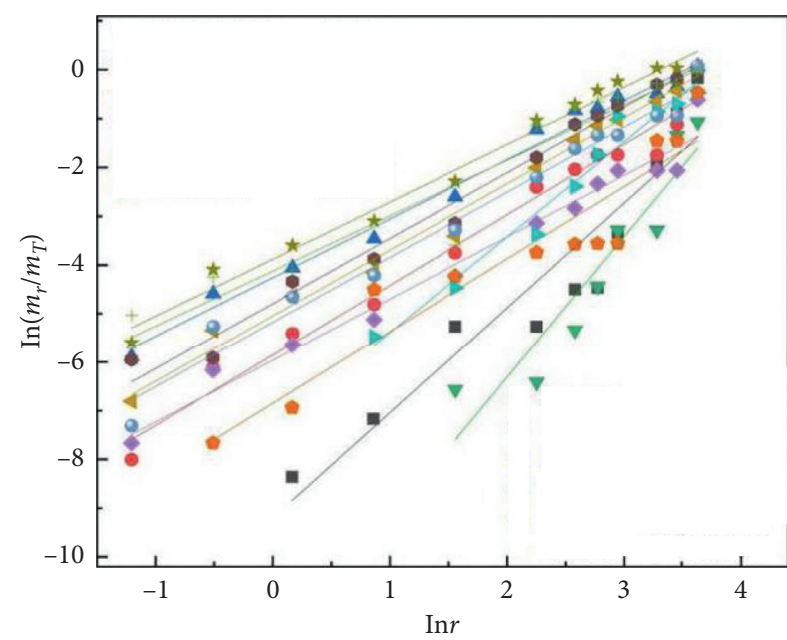

- NAC-C40-2, $R^{2}=0.88593$ N-SAC-C40-2, $R^{2}=0.96708$

- NAC-C $40-3, R^{2}=0.9739$ N-SAC-C $40-3, R^{2}=0.99839$

॥ NAC-C $40-4, R^{2}=0.986 \quad \star \mathrm{N}-\mathrm{SAC}-\mathrm{C} 40-4, R^{2}=0.98309$

$\checkmark$ NSFC-C40-2, $R^{2}=0.9582$ N-SC-C40-2, $R^{2}=0.8857$

- NSFC-C40-3, $R^{2}=0.97086$ N-SC-C40-3, $R^{2}=0.97617$

$\triangleleft$ NSFC-C40-4, $R^{2}=0.98835+\mathrm{N}-\mathrm{SC}-\mathrm{C} 40-4, R^{2}=0.91554$

(b)

FIgURE 16: $\ln \left(m_{r} / m_{T}\right)-\ln r$ curves. (a) C30 configuration strength. (b) C40 configuration strength.

The calculation formula of concrete fragmentation is as follows:

$$
\ln y=\ln \left(\frac{m_{r}}{m_{T}}\right)=b \ln \left(\frac{r}{r_{m}}\right)
$$

where $m_{r}$ stands for the cumulative mass of fragments with particle size less than $r, g ; m_{T}$ stands for the total amount of fragments, $g ; r_{m}$ stands for the maximum size of fragments, $\mathrm{mm} ; r$ stands for the fragment size, $\mathrm{mm}$; and $b$ stands for the distribution parameter, that is, the slope of the typical $\ln \left(m_{r} / m_{T}\right)-\ln r$ relationship curve.
Figure 16 is the typical $\ln \left(m_{r} / m_{T}\right)-\ln r$ relationship curve of each group of concrete under C30 and C40 configuration strengths. It can be seen from Figure 16 that the slope of the fitting curve between coal gangue concrete and ordinary concrete gradually decreases with the increase of impact pressure when the strength is C30 and C40. According to Figure 14, it can be found that the degree of fragmentation of the test piece is gradually increasing, and the proportion of small particle size fragments continues to increase, indicating that the mass distribution of the test piece continues to move to the small particle size end with the increase of impact pressure. 


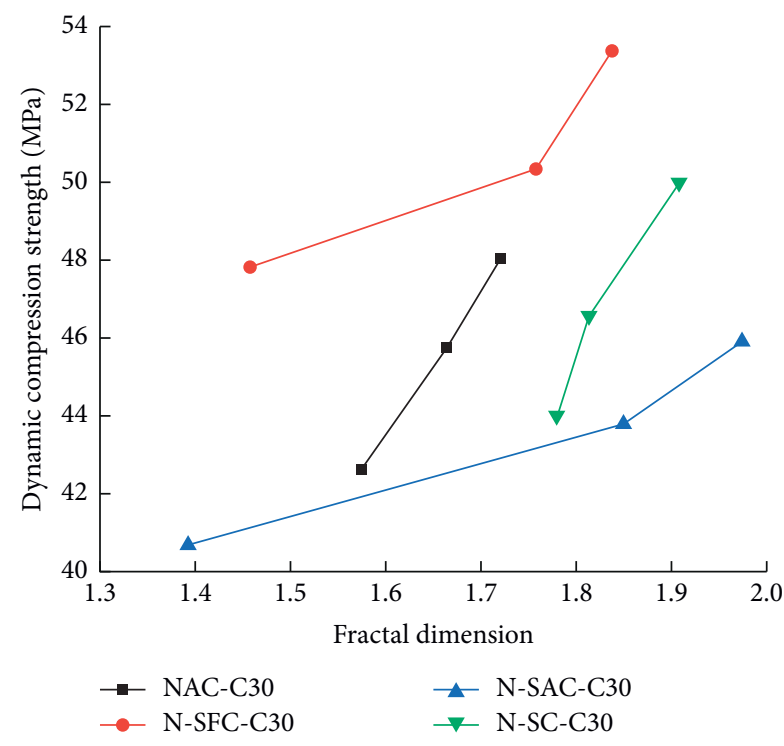

(a)

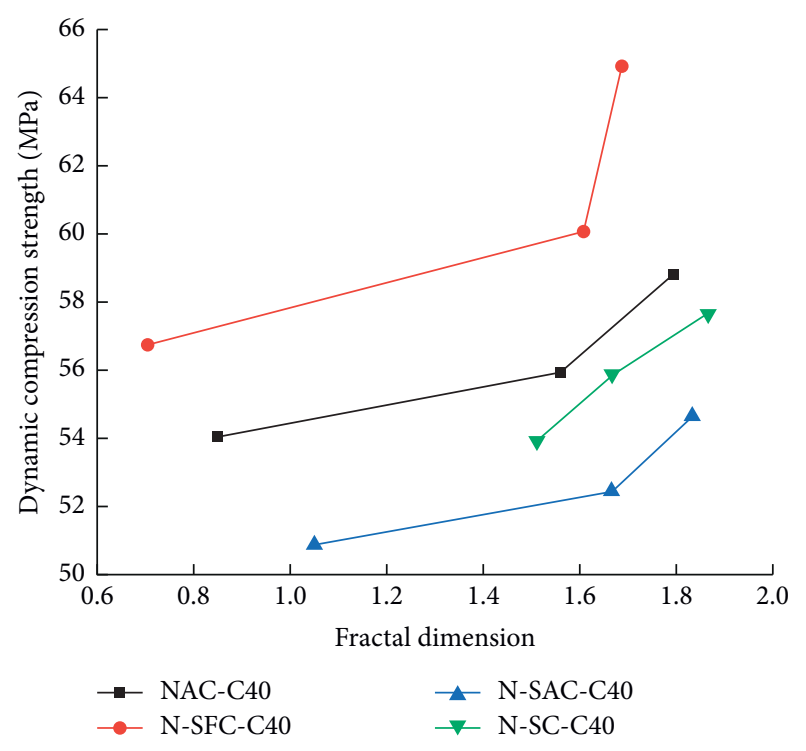

(b)

Figure 17: Relationship between fractal dimension and dynamic compressive strength index of concrete. (a) C30 groups. (b) C40 groups.

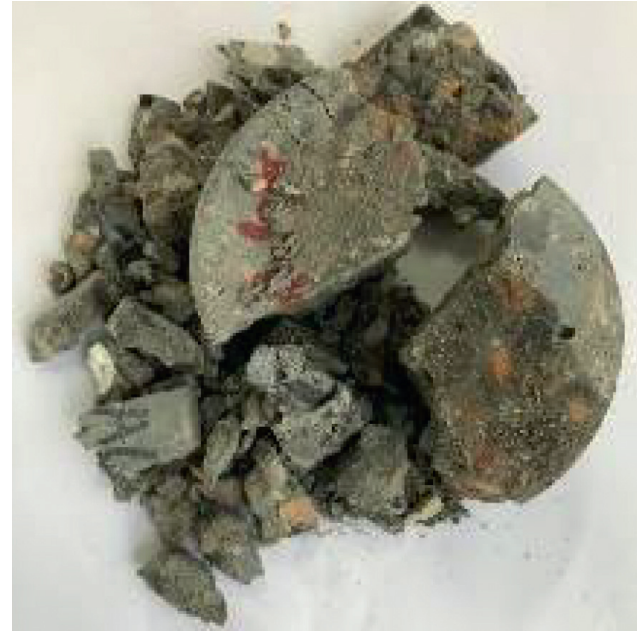

(a)

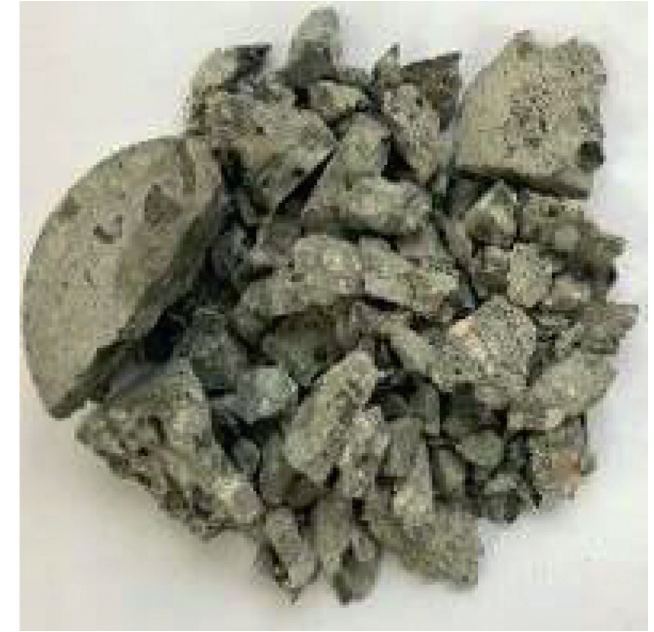

(b)

Figure 18: N-SFC and N-SAC after crushing. (a) N-SFC. (b) N-SAC.

According to the literature [34], the relationship between the fractal dimension $D$ of the concrete specimen damaged by impact and the slope $k$ of the typical $\ln \left(m_{r} / m_{T}\right)-\ln r$ curve corresponding to Figure 16 is $D=3-b$. Therefore, the representative data were selected to draw the relationship between the fractal dimension $D$ and its dynamic compressive strength index after the specimen was damaged under different impact pressures, as shown in Figure 17.

It can be seen from Figure 17 that, with the increase of the impact gas pressure, the fractal dimension of each group of concrete gradually increases, which is similar to the change trend of the dynamic compressive strength of concrete with the impact gas pressure. This shows that the higher the dynamic compressive strength of concrete, the larger the fractal dimension, and there is a good positive correlation between the fractal dimension of concrete and the dynamic compressive strength. This is due to the impact load being greater and the generation and evolution of internal defects and damage in the concrete being stronger, thus resulting in more complete damage, which increases the number of fragments, decreases the size of the specimen after impact damage, and then leads to the fractal dimension of the specimen increase.

Based on the above analysis, it can be found that, as shown in Figure 18(a), the fractal dimension of concrete single-doped with coal gangue fine aggregate is smaller; that is, the average size of broken particles is larger. As shown in Figure 18(b), the fractal dimension of concrete single-doped with coal gangue coarse aggregate is larger; that is, the average size of the broken particles is smaller. The reason is 
mainly related to the lower strength characteristics of coal gangue. For the concrete single-doped with coal gangue fine aggregate, under the impact load, due to the high strength of the coarse aggregate, the concrete cracks develop along the interface between the coarse aggregate and the mortar, so the broken concrete will form block distribution with block stone as the main body. For the concrete single-doped with coal gangue coarse aggregate because of the low strength of coal gangue coarse aggregate, the concrete cracks will develop along the interior of the block stone, so the concrete has a higher degree of fragmentation under dynamic load. Therefore, it can be concluded that, in the coal gangue concrete, when the coal gangue replaces the concrete fine aggregate, the concrete crushing degree is low; when the coal gangue replaces the concrete coarse aggregate, the concrete crushing degree is higher.

\section{Conclusions}

In order to study the feasibility of concrete doped with coal gangue in the application of mine supporting structure, in this research, coal gangue is used to replace coarse and fine aggregate in concrete, and its static (compressive strength) and dynamic (impact characteristics and dynamic compressive strength) characteristics are studied. The conclusions are as follows:

(1) According to the strength requirements of mine supporting concrete, the design strength of coal gangue concrete is $\mathrm{C} 30$ and $\mathrm{C} 40$, respectively. The results of the compressive strength test show that the uniaxial compressive strength of concrete singledoped with coal gangue coarse aggregate, singledoped with coal gangue fine aggregate, and codoped with coal gangue coarse and fine aggregates can meet the design strength requirements of $\mathrm{C} 30$ and $\mathrm{C} 40$ concrete, which indicates that it is feasible to use coal gangue to replace concrete fine aggregate and coarse aggregate or both to prepare C30 and C40 concrete.

(2) The initial and final crack impact energy of coal gangue concrete obtained by drop weight impact test are compared with that of ordinary concrete. Under the C30 design strength, the concrete single-doped with coal gangue fine aggregate increases by $22.9 \%$ and $11.4 \%$; the concrete single-doped with coal gangue coarse aggregate decreases by $15.2 \%$ and $15.4 \%$; the concrete codoped with coal gangue coarse and fine aggregates increases by $2.6 \%$ and $0.9 \%$, respectively. Under the C40 design strength, the concrete single-doped with coal gangue fine aggregate increased by $10.2 \%$ and $8.7 \%$, the concrete single-doped with coal gangue coarse aggregate decreased by $9.3 \%$ and $9.7 \%$, and the concrete codoped with coal gangue coarse and fine aggregates increased by $2.3 \%$ and $0.1 \%$, respectively. The main reason for this difference is that the coal gangue fine aggregate can optimize the force transfer structure of mortar and the coal gangue coarse aggregate can weaken the bearing structure of concrete.
(3) Comparing the dynamic compressive strength obtained by the SHPB impact test under $0.4-0.7 \mathrm{MPa}$ gas pressure with the static compressive strength, under the design strength of $\mathrm{C} 30$, the concrete single-doped with coal gangue fine aggregate increased by $9.8-30.4 \%$, the concrete single-doped with coal gangue coarse aggregate increased by 10.6-28.1\%, and the concrete codoped with coal gangue coarse and fine aggregates increased by 9.1-30.4\%. Under the design strength of C40, the concrete single-doped with coal gangue fine aggregate increased by $8.3-30.1 \%$, the concrete singledoped with coal gangue coarse aggregate increased by $13.2-25.8 \%$, and the concrete codoped with coal gangue coarse and fine aggregates increased by $11.0-26.1 \%$.

(4) According to the crushing characteristics of coal gangue concrete under different gas pressures, it can be found that, with the increase of gas pressure, the fractal dimension of coal gangue concrete increases and the degree of fragmentation increases. In addition, it can be found that the crushing degree of concrete with coal gangue coarse aggregate is greater than that with coal gangue fine aggregate, which can be explained by the fact that the lower strength of coal gangue may not limit the development of cracks.

\section{Data Availability}

The data used to support the findings of this study are included within the article.

\section{Conflicts of Interest}

The authors declare no conflicts of interest.

\section{Acknowledgments}

This research was supported by the National Natural Science Foundation of China (nos. 51674006 and 51778004), the Anhui University Discipline Professional Talented Person (no. gxbjZD09), Anhui Provincial Natural Science Foundation Youth Project (1908085QE185), Anhui Provincial College of Natural Science Research Key Project (KJ2018A0098), Project Funded by China Postdoctoral Science Foundation (2018M642502), and the Science Research Foundation for Young Teachers in Anhui University of Science and Technology (QN2017211).

\section{References}

[1] X. Huang, A. Zhou, W. Wang, and P. Jiang, "Characterization of the dynamic properties of clay-gravel mixtures at low strain level," Sustainability, vol. 12, no. 4, p. 1616, 2020.

[2] J. M. P. Q. Delgado, F. A. N. Silva, A. C. Azevedo, D. F. Silva, R. L. B. Campello, and R. L. Santos, "Artificial neural networks to assess the useful life of reinforced concrete elements deteriorated by accelerated chloride tests," Journal of Building Engineering, vol. 31, Article ID 101445, 2020. 
[3] L. Li, G. Long, K. Ma et al., "Preparation of green low strength mixture for foundation reinforcement treatment by using fly ash and waste coal gangue," Materials, vol. 13, no. 3, p. 664, 2020.

[4] M. Zhou, Y. Dou, Y. Zhang, Y. Zhang, and B. Zhang, "Effects of the variety and content of coal gangue coarse aggregate on the mechanical properties of concrete," Construction and Building Materials, vol. 220, pp. 386-395, 2019.

[5] Y. Zhang, Q. Wang, M. Zhou, Y. Fang, and Z. Zhang, "Mechanical properties of concrete with coarse spontaneous combustion gangue aggregate (SCGA): experimental investigation and prediction methodology," Construction and Building Materials, vol. 255, Article ID 119337, 2020.

[6] L. Qin and X. Gao, "Properties of coal gangue-Portland cement mixture with carbonation," Fuel, vol. 245, pp. 1-12, 2019.

[7] M. Xiao, F. Ju, and Z.-q. He, "Research on shotcrete in mine using non-activated waste coal gangue aggregate," Journal of Cleaner Production, vol. 259, Article ID 120810, 2020.

[8] Y. Zhang and T.-C. Ling, "Reactivity activation of waste coal gangue and its impact on the properties of cement-based materials - a review," Construction and Building Materials, vol. 234, Article ID 117424, 2020.

[9] H. Ma, H. Zhu, C. Wu, H. Chen, J. Sun, and J. Liu, "Study on compressive strength and durability of alkali-activated coal gangue-slag concrete and its mechanism," Powder Technology, vol. 368, pp. 112-124, 2020.

[10] R. Wu, S. Dai, S. Jian, H. Jun, H. Tan, and B. Li, "Utilization of solid waste high-volume calcium coal gangue in autoclaved aerated concrete: physico-mechanical properties, hydration products and economic costs," Journal of Cleaner Production, vol. 278, Article ID 123416, 2020.

[11] M. Hongqiang, C. Hongyu, Z. Hongguang et al., "Study on the drying shrinkage of alkali-activated coal gangue-slag mortar and its mechanisms," Construction and Building Materials, vol. 225, pp. 204-213, 2019.

[12] L. Li, G. Long, C. Bai, K. Ma, M. Wang, and S. Zhang, "Utilization of coal gangue aggregate for railway roadbed construction in practice," Sustainability, vol. 12, no. 11, p. $4583,2020$.

[13] Chinese Standard GB/T 50107-2010, "China ministry of housing and urban-rural development," Standard for Evaluation of Concrete Compressive Strength, China Construction Industry Press, Beijing, China, 2010, in Chinese.

[14] W. L. Li, "Experimental study on strength and crack resistance of coal gangue aggregate concrete mixed with glass fiber and fly ash," Building Structure, vol. 50, no. 13, pp. 49-53, 2020.

[15] Y. J. Li, C. Pan, S. K. Zhang, D. H. Li, H. T. Guan, and Z. S. Zhang, "Experimental study on damage of coal gangue concrete under cyclic load," Bulletin of the Chinese Ceramic Society, vol. 38, no. 08, pp. 2531-2535, 2019.

[16] H. Ma, H. Zhu, H. Chen, Y. Ni, X. Xu, and Q. Huo, "Shrinkage-reducing measures and mechanisms analysis for alkali-activated coal gangue-slag mortar at room temperature," Construction and Building Materials, vol. 252, Article ID 119001, 2020.

[17] J. X. Zhang, W. L. Chen, and R. J. Yang, "Experimental study on basic properties of coal gangue aggregate," Journal of Building Materials, vol. 6, no. 13, pp. 739-743, 2010.

[18] C.-l. Wang, W. Ni, S.-q. Zhang, S. Wang, G.-s. Gai, and W.-k. Wang, "Preparation and properties of autoclaved aerated concrete using coal gangue and iron ore tailings," Construction and Building Materials, vol. 104, no. 104, pp. 109-115, 2016.

[19] M. Zhou, G. N. Li, Q. Zhang, and H. B. Cui, "Study on application of spontaneous combustion coal gangue aggregate in ready-mixed concrete," Journal of Building Materials, vol. 5, no. 18, pp. 830-835, 2015.

[20] J.-X. Lin, Y. Song, Z.-H. Xie et al., "Static and dynamic mechanical behavior of engineered cementitious composites with PP and PVA fibers," Journal of Building Engineering, vol. 29, Article ID 101097, 2020.

[21] G. Murali, R. Gayathri, V. R. Ramkumar, and K. Karthikeyan, "Two statistical scrutinize of impact strength and strength reliability of steel fibre-reinforced concrete," KSCE Journal of Civil Engineering, vol. 22, no. 1, pp. 257-269, 2018.

[22] Y. Hao, H. Hao, G. P. Jiang, and Y. Zhou, "Experimental confirmation of some factors influencing dynamic concrete compressive strengths in high-speed impact tests," Cement and Concrete Research, vol. 52, pp. 63-70, 2013.

[23] A. Badr, A. F. Ashour, and A. K. Platten, "Statistical variations in impact resistance of polypropylene fibre-reinforced concrete," International Journal of Impact Engineering, vol. 32, no. 11, pp. 1907-1920, 2006.

[24] S. Lee, K.-M. Kim, J. Park, and J.-Y. Cho, "Pure rate effect on the concrete compressive strength in the split Hopkinson pressure bar test," International Journal of Impact Engineering, vol. 113, pp. 191-202, 2018.

[25] T. Abirami, M. Loganaganandan, G. Murali et al., "Experimental research on impact response of novel steel fibrous concretes under falling mass impact," Construction and Building Materials, vol. 222, pp. 447-457, 2019.

[26] S. R. Abid, M. L. Abdul-Hussein, N. S. Ayoob, S. H. Ali, and A. L. Kadhum, "Repeated drop-weight impact tests on selfcompacting concrete reinforced with micro-steel fiber," Heliyon, vol. 6, no. 1, Article ID e3198, 2020.

[27] M. Nili and V. Afroughsabet, "Combined effect of silica fume and steel fibers on the impact resistance and mechanical properties of concrete," International Journal of Impact Engineering, vol. 37, pp. 879-886, 2010.

[28] Y. B. Lu and Q. M. Li, "A correction methodology to determine the strain-rate effect on the compressive strength of brittle materials based on SHPB testing," International Journal of Protective Structures, vol. 2, no. 1, pp. 127-138, 2011.

[29] Chinese Standard JGJ 55-2019, "China ministry of housing and urban-rural development," Specification for Mix Proportion Design of Ordinary Concrete, China Construction Industry Press, Beijing, China, 2019, in Chinese.

[30] C. Liu, X. Deng, J. Liu, and D. Hui, "Mechanical properties and microstructures of hypergolic and calcined coal gangue based geopolymer recycled concrete," Construction and Building Materials, vol. 221, no. 221, pp. 691-708, 2019.

[31] Chinese Standard GB/T 50081-2019, "China ministry of housing and urban-rural development," Standard for Test Methods of Concrete Physical and Mechanical Properties, China Construction Industry Press, Beijing, China, 2019, in Chinese.

[32] S. Feng, Y. Zhou, Y. Wang, and M. Lei, "Experimental research on the dynamic mechanical properties and damage characteristics of lightweight foamed concrete under impact loading," International Journal of Impact Engineering, vol. 140, Article ID 103558, 2020.

[33] M. Z. N. Khan, Y. Hao, H. Hao, and F. u. A. Shaikh, "Mechanical properties and behaviour of high-strength plain and hybrid-fiber reinforced geopolymer composites under dynamic splitting tension," Cement and Concrete Composites, vol. 104, Article ID 103343, 2019.

[34] P. Liu, D. Hu, Q. Wu, and X. Liu, "Sensitivity and uncertainty analysis of interfacial effect in SHPB tests for concrete-like materials," Construction and Building Materials, vol. 163, pp. 414-427, 2018. 